Federal Reserve Bank of Dallas

Globalization and Monetary Policy Institute

Working Paper No. 248

http://www.dallasfed.org/assets/documents/institute/wpapers/2015/0248.pdf

\title{
Multinational Firms' Entry and Productivity: Some Aggregate Implications of Firm-level Heterogeneity ${ }^{*}$
}

\author{
Silvio Contessi \\ Monash Business School
}

September 2015

\begin{abstract}
Despite the microeconomic evidence supporting the superior idiosyncratic productivity of multinational firms (MNFs) and their affiliates, cross-country studies fail to find robust evidence of a positive relationship between foreign direct investment and growth. In order to study the aggregate implications of MNFs entry and production, I develop a dynamic general equilibrium model with firm heterogeneity where MNFs sort according to their own productivity. The entry and production of MNFs contribute to aggregate productivity growth at decreasing rates and affect domestic producers through general equilibrium effects in the labor market. I argue that the heterogeneous composition of the population of affiliates can help explain the conflicting evidence on the impact of foreign direct investment on growth.
\end{abstract}

JEL codes: F21, F23, F41, F42

\footnotetext{
* Silvio Contessi, Monash Business School, Department of Banking and Finance, P.O. Box 197, Caulfield East, VIC 3145. Silvio.contessi@monash.edu. +61-3-9903-4946. I am grateful for the comments of participants at several seminars and conferences, and especially to one of the anonymous referees, to the Editor of this journal, Fabio Ghironi, Pravin Krishna, Thomas Lubik, Kathryn Russ, Viktors Stebunovs, and Andrei Zlate. Part of this project was completed when the author was an economist at the Federal Reserve of St. Louis. The views in this paper are those of the author and do not necessarily reflect the views of the Federal Reserve Bank of Dallas or the Federal Reserve System.
} 


\section{Introduction}

Entry of multinational producers is now common throughout the world, thanks in part to the implementation of a wave of regional integration agreements, the consolidation of the European Single Market, and the General Agreement on Trade in Services of 1994. The past three decades, in particular, have witnessed a formidable growth in the volume of multinational production and capital across industrial and emerging countries. Most of the existing theoretical literature favors the idea that the entry and production of multinational firms (MNFs) through foreign direct investment (FDI) contribute positively to the productivity level and growth of the host economies (see, for example, Rivera-Batiz and Rivera-Batiz, 1990; Borensztein, De Gregorio, and Lee; 1998; and Alfaro et al., 2010). However, an abundant empirical literature studying the relationship between FDI and growth has not been able to establish a robust positive relationship between the two variables using cross-country or panel regressions. Kose et als. (2009) survey of numerous empirical cross-country studies finds only one study reporting a positive impact of FDI on economic growth: "We turn next to the presumed poster child for the benefits of financial globalization-FDI... There is a strong presumption in theory that FDI should yield more benefits than other types of financial flows since, in addition to augmenting domestic capital stock, it has a positive impact on productivity through transfers of technology and managerial expertise... A large empirical literature has flourished seeking to find evidence in support of the theoretical benefits of these flows. Although the evidence has in general been mixed, recent studies, using more sophisticated methodologies and micro-level datasets, find more favorable evidence of benefits from FDI." Similarly, Harrison and Rodriguez-Clare (2010) conclude their review noting that "Nevertheless, there is generally mixed evidence on the relationship between FDI and a country's growth."11 Researchers who use aggregate data normally postulate that the aggregate

\footnotetext{
${ }^{1}$ See also the survey of Carkovic and Levine (2005). In addition to supplying mixed results, the evidence from growth regressions suffers from the common problems that plague growth cross-country and panel regressions: endogeneity, parameter heterogeneity, outliers, model uncertainty, measurement error, and aggregation issues as discussed in Bloningen and Wang (2005) and, in the broader context of the relationship between economic policy and growth, by $\operatorname{Rodrik}(2012)$.
} 
production function is a Cobb-Douglas function. Estimated equations take a form similar to $\dot{Y}_{j}=\alpha+\beta_{0} * F D I_{j}+\beta_{1}\left(F D I_{j} * x_{j}\right)+\gamma X_{j}+\epsilon_{j}$, in which $\dot{Y}_{j}$ is Gross Domestic Product (GDP) or GDP growth, $\alpha$ is a constant, $F D I_{j}$ is a measure of the presence of MNFs, the matrix $X_{j}$ contains a number of non-MNFs-related factors assumed to affect growth, and the interaction term $\left(F D I_{j} * x_{j}\right)$ accounts for possible interactions between FDI and other non-FDI factors that are assumed to affect growth. Researchers then test whether the estimated coefficient is positive and significant in the regression and generally fail to find evidence supporting the notion that FDI contributes to growth. It is fair to argue that the only way to obtain positive significant coefficients is to postulate that FDI contributes to growth when some other conditions are present, such as a sufficient level of human capital, financial development, and export orientation. However, even when these variables are included in cross-country regressions, the evidence is far from robust. Figure For example, 1 plots the relationship between FDI stocks to gross domestic product (GDP) ratios and real GDP growth for the 1990-2000 and the 2000-05 periods for 110 and 132 countries (depending on data availability). Without using formal econometric analyses, identifying the sign of the relationship between these two variables in aggregate data is arduous.

[Figure 1 here]

This difficulty in finding evidence of a positive relationship between FDI and growth is puzzling (see also McGrattan, 2012) because, aside from theoretical arguments, at least three strands of the empirical literature on FDI suggest a productivity superiority of multinationals relative to non-multinational parents and affiliates. First, aggregate data suggest that affiliates of MNFs appear to have higher labor productivity levels in countries for which aggregate data are available, mainly those belonging to the Organisation for Economic Co-operation and Development (OECD; Criscuolo, 2005) and in the United States (Corrado, Lengermann, and Slifman, 2009).

Second, a large segment of the literature has documented a positive relationship between multinational status and own productivity in firm- and plant-level data. For example, Arnold 
and Javorcik (2009) find that foreign ownership leads to significant increases in the productivity of newly acquired affiliates in Indonesia, as well as improvement in every other observable dimension, including higher productivity growth, higher investment, and higher sales growth. Harrison and Rodriguez-Clare (2010) conclude that "Most researchers find that the own-plant effect is large and significant. In other words, firms with foreign equity participation typically have higher output, higher output per worker, or higher levels of TFP" [Total Factor Productivity] $2^{2}$

Third, several studies suggest that MNFs and affiliates are more productive than locally oriented firms. For industrial countries, Criscuolo and Martin (2009) and Bloom, Sadun, and Van Reenen (2012) show that affiliates of MNFs in the United States have a clear idiosyncratic total factor productivity advantage over domestic firms, U.K. MNFs, and other countries' affiliates in the United Kingdom. The evidence favors a similar relationship for non-advanced economies as well 3

This body of evidence prompts the following question: Why does the positive relationship between FDI and growth not emerge in growth regressions?

In this paper, I argue that this seemingly conflicting evidence can be reconciled in a general equilibrium dynamic model of multinational entry with firm heterogeneity that contains the key ingredients of the models of Hopenhayn (1992) and Melitz (2003) and is consistent with the empirical literature just discussed. In the two-country model I develop, I can examine the general equilibrium effects of two conflicting mechanisms through which multinational production affects the host economy when firms are heterogeneous in productivity: contribution to productivity growth due to technology transfer and decreasing productivity of new affiliates due to the combination of fixed costs of multinational production and heterogenous productivity of affiliates.

\footnotetext{
${ }^{2}$ While the firm- and plant-level literature finds a robust positive relationship in levels between foreign ownership and own productivity, the evidence on the effect of foreign-owned firms on domestic firms productivity is mixed (Görg and Greenaways, 2004), and therefore I omit these effects in the rest of the paper.

${ }^{3}$ See also Chapter 7.3 of Barba Navaretti and Venables (2004).
} 
I study these mechanisms using a general equilibrium model that returns $(\log )$ linear relationships akin to the linear regressions in the empirical literature just discussed. In doing so, I abstract from international trade to clearly focus on the implications of heterogeneity of affiliate firms on aggregate productivity. This is the main difference with respect to Ghironi and Melitz (2005) that employs a similar macroeconomic structure (discussed below) but a different structure of firms' global engagement in that they focus entirely on production as well as labor demand focused on the home economy, from which firms export. Here, I consider market-seeking horizontal MNFs (akin to service multinationals such as Wal-Mart) for three reasons 4 First, market-seeking horizontal entry dominates flows from developed nations and tends to substitute trade at the product level (Swenson, 2004), generating little international trade compared with resource-seeking vertical FDI (Hanson and Slaughter, 2004). Second, even in a north-south context, the magnitude of vertical fragmentation can be reasonably expected to be small relative to market-seeking operations (Borga and Zeile, 2004). Though relatively small until the late 1990s, vertical fragmentation - either within multinational firms' boundaries or through outsourcing - has grown in the past two decades, particularly for manufacturing industries; Zlate (2010) develops a general equilibrium model with heterogeneous firms and outsourcing to study this phenomenon and shows that it has quantitatively relevant effects in the transmission of shocks across borders. Finally, the share of outward (horizontal) FDI in services and nontradable sectors has outgrown tradegenerating manufacturing entry, and only a fraction of the output of the services sector is composed of tradables (Bradford Jensen and Kletzer, 2005). In the early 1970s, services accounted for only $25 \%$ of the world FDI stock; in 1990 this share was less than 50\%; and by 2002 , it had risen to about $60 \%$.

\footnotetext{
${ }^{4}$ The key elements of the model presented in this paper are mirrored in a detailed case study by Javorcik, Keller, and Tybout (2008) on the soap and detergents industry in Mexico. The authors document the importance of the North American Free Trade Agreement (NAFTA) in triggering the entry of Wal-Mart and other foreign retailers into the country, a process that eventually revolutionized different industries by "shaking up" the distribution sector and triggering upstream innovation and firm selection. Other examples in the Mexican retailing sector include the 1991 joint venture of Aurrera with Wal-Mart, the 1992 joint venture of Comercial Mexicana with Price-Costco, and the 1994 joint venture of supermarket chain Gigante with Carrefour and Office Depot. According to Javorcik, Keller, and Tybout (2008), only one large supermarket chain, Soriana, remained domestically owned in Mexico in the mid-1990s.
} 
In this paper, firms are characterized by heterogeneous productivity levels. If they incur a fixed cost to become multinational and this cost either decreases over time because of FDI liberalization or the attractiveness of foreign markets increases due to aggregate productivity growth, then entrants sort according to their own idiosyncratic productivity in response to changes in the aggregate conditions of the host economy and in the entry costs. The most productive firms become MNFs earlier, whereas firms that are relatively less productive enter host economies later, as documented by Yeaple (2009) using firm-level data for U.S. MNFs 5

MNFs respond to positive aggregate productivity shocks and/or FDI liberalization in two ways ${ }^{6}$ At the intensive margin, existing multinational producers increase sales as the host country economy booms in response to the domestic positive shocks. At the extensive margin, higher productivity reduces the fixed cost of entry, attracting new affiliates in the host economy, hence adding the affiliates' production to the output of the existing firms. Entry of relatively less productive firms then reduces the average productivity of the "multinational sector" in the host economy, simultaneously as the stock of MNFs increases. Hence, while countries with larger stocks of FDI are expected to grow faster, the contribution of MNFs to the host countries' productivity level and growth actually decreases. Thus, increased multinational entry does not necessarily translate into a larger benefit for the host country because of the decreasing rate of productivity contributions and because entry boosts labor demand, which in turn penalizes existing domestic firms by increasing wages in the host economy (Figlio and Bloningen, 2000, for evidence).

This model highlights a tension between the issue of cyclical determinants and the steadystate share of multinational production because it delivers both a steady-state calibration and impulse-responses to observe the dynamic effect of changes in exogenous variables on endogenously determined variables. Calibrating the steady-state of the model mirrors the

\footnotetext{
${ }^{5}$ Specifically, this study shows that a $10 \%$ increase in a host country's GDP is associated with a $5.4 \%$ increase in the number of U.S. firms owning an affiliate there but a $1.4 \%$ decrease in the average productivity of the entrants.

${ }^{6}$ Though I do not insist on this interpretation in the paper, because I simply use aggregate productivity shocks to show how endogenous variables move when the economy is outside the steady state, the recent work of Bai et al. (2012), allows also justifying this shock as a demand shock.
} 
fact that different countries have barriers to FDI of different magnitudes, which in turn affects their steady-state endogenous variables. Each calibrated steady state returns different shares of MNFs and multinational production in the total population of firms, as well as different levels of measured productivity and output, and can be interpreted as representing different countries.7

The relationship among steady-steady multinational presence, measured productivity, and output is nonlinear: For a large multinational presence, the contribution of entry to measured productivity is negative as the new entrants are relative less productive than existing producers, while this relationship is positive when the multinational presence is limited. This result echoes the empirical work of Bloningen and Wang (2005), who argue that the pooling of countries characterized by different levels of development - and presumably of multinational presence - should be done carefully in empirical FDI studies, as the empirical relationship between FDI and growth depends on the level of development of the host country. In addition, the impulse-response exercises allow the evolution of the endogenous variables to be tracked when the model is shocked out of its steady-state. This could be considered analogous to growth accelerations and decelerations or even just cyclical movements. I argue that the empirical puzzle stems from the fact that cross-country regressions pick up both differences in the steady-state level of the endogenous variables - ultimately determined by exogenous parameters in the model - and the effect of short-term fluctuations which, in this simple model, are generated by shocks to aggregate productivity or changes in incentives to attract FDI in the host economy. For example, a permanent reduction of the fixed cost of multinational production produces effects similar to a permanent increase in aggregate productivity, changing the steady-state level of the endogenous variables. A temporary increase in aggregate productivity, however, produces similar effects in the short period but

\footnotetext{
${ }^{7}$ As customary in the literature and as discussed later, for an individual producer, measured productivity is the product of an unobservable aggregate (or common across firms) productivity component $Z_{t}$ and an idiosyncratic producer-specific productivity parameter $z$. Accordingly, the weighted average measured productivity of producers is the theoretical counterpart of the measured aggregate productivity, which is conventionally estimated from aggregate data. It should be noted that this measured productivity depends on the composition of the population of active producers induced by selection (Ghironi and Melitz, 2005).
} 
mean-reverts in the long period, bringing the system back to its original equilibrium. Traditional growth regression likely capture both effects (transitional dynamics and steady-state changes) and with potentially conflicting effects on the sign of the estimated coefficients, a fact that should be observed when considering the empirical evidence. In addition, this model suggests that further insight could be gained from reconstructing aggregate productivity from firm-level data, using approaches developed in the empirical industrial organization literature; see, for example, Petrin and Levinsohn (2012) and especially Rodrigue (2014) that structurally estimates a model of multinational production and exports with heterogeneous firms using a panel of Indonesian manufacturing plants.

The paper is structured as follows. I develop the model in Section 2 and discuss how to solve it in Section 3 . I present the dynamic properties of this economy in Section 4 and discuss the relationship among multinational entry and production, productivity, and growth in Section 5. Section 6 concludes.

\section{The Model}

I adopt a popular approach in international trade and model monopolistically competitive firms that are heterogeneous in their idiosyncratic productivity, similar to the model developed in Melitz (2003) and Ghironi and Melitz (2005) in its macroeconomic structure. $\$^{8}$ Here, firms face uncertainty about their individual productivity when they make an irreversible investment to enter the domestic market by paying a sunk entry cost. In addition, at any point in time, the composition of the multinational sector is pinned down endogenously by the microeconomic structure and determined by the interaction of the per-period fixed cost to produce in the foreign market, the dispersion of productivity, and the elasticity of substitution among goods' varieties. Over time, firms enter and exit the domestic market and

\footnotetext{
${ }^{8}$ See also a survey of recent theories of foreign direct investment in Russ $(2009)$ and Ramondo and Rappoport (2010). In a static partial equilibrium framework, other contributions relating FDI and heterogeneous productivity include those of Helpman, Melitz, and Yeaple (2004), Yeaple (2009), Cole and Davies (2011) and Wang, Wen, and $\mathrm{Xu}$ (2012). For a study of the relationship between firm heterogeneity and exchange rates in a dynamic framework, see Naknoi (2015).
} 
produce and discontinue production in the foreign market as shocks to aggregate productivity interact with entry and fixed costs, making the pattern of MNFs entry endogenous. Given the motivation of the paper, I consider multinational production as the only channel of foreign sales, but the results also hold in an environment in which affiliates choose between exporting to the foreign country and selling to foreign consumers through foreign affiliates (see Contessi, 2007, for a model with these features).

\subsection{Consumers}

\subsubsection{Intertemporal Problem}

I model the world as a two-country economy with a simple macroeconomic structure: Prices are perfectly flexible, contracts are written in nominal terms and consumers have identical Dixit-Stiglitz preferences over a measure $\Omega$ of varieties in each period. The utility function is based on Greenwood, Hercowitz, and Huffman (1988) and is characterized by constant relative risk aversion over a bundle of the constant elasticity of substitution consumption aggregator $\left(C_{t}\right)$ and the number of hours worked $\left(L_{t}\right)$.9 Individuals face the following intertemporal optimization problem in real terms, derived using the aggregate price level in the home economy $P_{t}$ as the numeraire:

$$
\begin{gathered}
\max _{\left\{C_{t}, x_{t}, B_{t}, L_{t}\right\}_{t=0}^{\infty}}\left[E_{t} \sum_{t=0}^{\infty} \beta^{t} \frac{1}{1-\gamma}\left(C_{t}-\frac{L_{t}^{\chi}}{\chi}\right)^{1-\gamma}\right] \\
C_{t}+\widetilde{v}_{t} N_{H, t} x_{t+1}+B_{t+1}^{H}=w_{t} L_{t}+\left(\widetilde{v}_{t}+\widetilde{\pi}_{t}\right) N_{D, t} x_{t}+\left(1+r_{t} i\right) B_{t}^{H}
\end{gathered}
$$

The per-period constant relative risk aversion utility is discounted with a discount factor $\beta \in(0,1), \gamma>0$ is the relative risk aversion parameter, $\chi$ is the elasticity of labor supply, $e_{t}$ and $Q_{t}=e_{t} P_{t}^{*} / P_{t}$ are the nominal and real exchange rates; $e_{t}$ is equal to the units of home currency necessary to buy one unit of foreign currency, while $Q_{t}$ represents the units

\footnotetext{
${ }^{9}$ With this particular specification for the per-period utility function, the wealth effect on the labor supply is removed, so that the latter only depends on the wage level and not on consumption and the interest rate.
} 
of home consumption per unit of foreign consumption. I assume that households hold only two financial instruments: (i) shares in a mutual fund of domestic firms $x_{t}$ and (ii) domestic risk-free bonds $B_{t}^{H}$ that yield a risk-free interest rate $r_{t}$.

In each period, entrepreneurs earn real profits $\frac{\widetilde{\Pi}_{t}}{P_{t}}=\widetilde{\pi}_{t}$ from a number $N_{D, t}$ of domestic varieties they produce. Households finance their expenditures earning labor income $w_{t} L_{t}$ and cashing the principal and interest on the bonds bought in the previous period $\left(1+r_{t}\right) B_{t}^{H}$ and the shares and profits $\widetilde{v}_{t} x_{t}$ and $\widetilde{\pi} x_{t}$ of the mutual fund that owns all the individual producers of the $N_{D, t}$ varieties. Finally, $\widetilde{v}_{t}$ is the average firm value that, as discussed below, potential entrants compare to the present discount values of the expected stream of future profits, and ultimately determines the number of entrants in each period.

Based on the intertemporal optimization problem, I can define two Euler equations for bond and share holdings:

$$
\begin{gathered}
{\left[\frac{E_{t}\left(C_{t+1}-\frac{L_{t+1}^{\chi}}{\chi}\right)}{C_{t}-\frac{L_{t}^{\chi}}{\chi}}\right]^{\gamma}=\beta\left(1+r_{t+1}\right)} \\
\beta(1-\delta) E_{t}\left[\left(\frac{C_{t+1}-\frac{L_{t+1}^{\chi}}{\chi}}{C_{t}-\frac{L_{t}^{\chi}}{\chi}}\right)^{-\gamma}\left(\widetilde{v}_{t+1}+\widetilde{\pi}_{t+1}\right)\right]=\widetilde{v}_{t} .
\end{gathered}
$$

Notice that the intertemporal discount factor $\beta$ is scaled by a component $\delta$ that captures the probability of firms' death, similar to Melitz (2003).

\subsubsection{Intratemporal Problem}

In each period, consumption takes place over a continuum of goods indexed by $\omega \in \Omega$ and aggregated as $C_{t}=\left(\int_{\omega \in \Omega} y_{t}(\omega)^{\frac{\sigma-1}{\sigma}} d \omega\right)^{\frac{\sigma}{\sigma-1}}$, to which is associated a standard Constant Elasticity of Substitution (CES) price aggregator $P_{t}=\left(\int_{\omega \in \Omega_{t}} p_{t}(\omega)^{1-\sigma} d \omega\right)^{\frac{1}{1-\sigma}}$, where $\sigma>$ 1 is the symmetric elasticity of substitution across goods. The demand for a variety is $y_{t}(\omega)=\left(\frac{p_{t}(\omega)}{P_{t}}\right)^{-\sigma} C_{t}$. Thus, in the CES demand system, expenditure on an individual home or foreign good is proportional to total consumer expenditure. Identical optimization problems, 
resource constraints, Euler equations, price aggregators, and the demand system characterize the foreign economy and are identified with an asterisk.

\subsection{Production}

\subsubsection{Domestic Entry}

Consider the home country. In each period, a mass of potential entrants can enter production. I use goods, varieties, products, firms, and entrepreneurs as substitutes, each produced by a different single-product manufacturing unit. Entrants in time $t$ start producing in $t+1$. However, both existing and new varieties can be hit by an exogenous "death" shock with probability $\delta$ after entry. ${ }^{10}$ The number of produced varieties is equal to the survivors from the existing stock and new products:

$$
N_{D, t}=(1-\delta)\left(N_{D, t-1}+N_{E, t-1}\right)
$$

I assume that entrepreneurs know $\delta$ and that they are forward looking, with the implication that the expected profit is exactly the realized average profit, $E_{t}\left[\pi_{s}(z)\right]=\widetilde{\pi}_{s}(z), s>t$. Within this framework, potential entrants evaluate their expected post-entry value with the present discounted value of the expected stream of future profits $\left\{\widetilde{\pi}_{s}\right\}_{s=t+1}^{\infty}$,

$$
\widetilde{v}_{t}=E_{t} \sum_{s=t+1}^{\infty}[\beta(1-\delta)]^{s-t}\left(\frac{C_{t+s}}{C_{t}}\right)^{-\gamma} \widetilde{\pi}_{s},
$$

which is equal to the average value after entry and production.

Before entering production of a specific variety, each entrepreneur faces a sunk entry cost of $f_{E, t}$ effective labor units equal to $\frac{W_{t} f_{E, t}}{Z_{t}}$ units of the home consumption good. Upon entry the entrepreneur draws the idiosyncratic relative productivity level $z$ from a common distribution $G(z)$. The producer of each variety of goods maintains its relative productivity until it exits the market - namely, until it is hit by the death shock. The exit of varieties is thus

\footnotetext{
${ }^{10}$ This implies that a share $\delta N_{E}$ of the new firms will never produce.
} 
independent of the productivity level. Notice that in this model idiosyncratic productivity does not evolve over time. This amounts to assuming that each variety is born with a specific production process (i.e., productivity) that does not change unless the variety ceases to exist because of changes in consumer tastes or obsolescence. Hence, a higher-quality specification of a variety becomes an entirely new good, $\omega \in \Omega$, with a specific $z$ drawn from $g(z)$.

The free entry condition requires that the firm value is equalized with the entry cost

$$
\widetilde{v}_{t}=\frac{w_{t} f_{E, t}}{Z_{t}},
$$

measured in units of consumption after multiplication by the real wage and division by aggregate productivity.

\subsubsection{Domestic Production and Multinational Entry}

On the production side of the economy, each variety is produced by a different entrepreneur under increasing returns to scale with a fixed cost and a heterogeneous and time-varying marginal cost for the single factor of production, labor $l_{t}(z)$. The output of each producer is influenced not only by aggregate (or common) productivity $Z_{t}$, but also by an idiosyncratic (relative) productivity parameter $z$ that enters the cost function as follows:

$$
\Gamma_{D, t}(\omega)=W_{t} l_{t}(z)=\underbrace{\frac{W_{t}}{z Z_{t}} y_{D, t}(\omega)}_{\text {variable cost }} .
$$

Here, $l_{D, t}(z)=y_{t}(\omega) / z Z_{t}$ is the total labor requirement needed to produce a quantity $y_{t}(\omega)$ of output that is sold domestically. Notice that $Z_{t}$ is common for all varieties and changes over time, whereas $z$ is variety specific and time invariant. This cost function implies that productivity differences across products translate into differences in the unit cost of production. The latter is measured in units of the consumption good and equals $w_{t} / z Z_{t}$, where $w_{t}$ is the real wage $W_{t} / P_{t}$. Labor mobility within countries ensures domestic wage equalization across producers, and international immobility of workers prevents agglomeration. 
Producers can also engage in multinational production for the delivery of a variety abroad by setting up a manufacturing unit in the other country and hiring foreign labor (paid at a foreign wage rate) at the cost of an annualized fixed cost $f_{I, t}$ in terms of effective labor units equal to $\frac{W_{t}^{*} f_{I, t}^{*}}{Z_{t}^{*}}$ units of the foreign consumption good 11 Hence, their cost structure is

$$
\Gamma_{I, t}(\omega)=W_{t}^{*} l_{I, t}^{*}(z)=\underbrace{\frac{W_{t}^{*} f_{I, t}^{*}}{Z_{t}^{*}}}_{\text {fixed cost of multinational production }}+\underbrace{\frac{W_{t}^{*}}{z Z_{t}^{*}} y_{I, t}^{*}(\omega)}_{\text {variable cost of multinational production }} .
$$

I can break down the per-period optimization problem for each market as

$$
\begin{gathered}
\max _{p_{D, t}(\omega)} \Pi_{D, t}=p_{D, t}(\omega) y_{D, t}(\omega)-\frac{W_{t}}{Z_{t} z} y_{D, t}(\omega) \\
\max _{p_{I, t}(\omega)} \Pi_{I, t}=e_{t}\left[p_{I}(\omega) y_{I, t}^{*}(\omega)-\frac{W_{t}^{*}}{Z_{t}^{*} z} y_{I, t}^{*}(\omega)-\frac{W_{t}^{*} f_{I, t}^{*}}{Z_{t}^{*}}\right] .
\end{gathered}
$$

Optimal prices for each group of firms are

$$
p_{D, t}(\omega)=\mu \frac{W_{t}}{z Z_{t}}, \quad p_{I, t}(\omega)=\mu \frac{W_{t}^{*}}{z Z_{t}^{*}} .
$$

Thus, the prices for each variety $\omega$, relative to the price index of the market of destination, are expressed as follows:

$$
\rho_{D, t}(\omega)=\frac{p_{D, t}(\omega)}{P_{t}}=\mu \frac{w_{t}}{z Z_{t}}, \quad \rho_{I, t}(\omega)=\frac{p_{I, t}(\omega)}{P_{t}^{*}}=\mu \frac{w_{t}^{*}}{z Z_{t}^{*}} .
$$

Associated with these optimal prices, I can define the optimal profits for each segment as follows

$$
\begin{aligned}
\Pi_{D, t}(\omega) & =p_{D, t}(\omega)\left[\rho_{D, t}(\omega)\right]^{-\sigma} \frac{C_{t}}{\sigma} \\
\Pi_{I, t}(\omega) & =\varepsilon p_{I, t}(\omega)\left[\rho_{I, t}(\omega)\right]^{-\sigma} \frac{C_{t}^{*}}{\sigma}-\frac{W_{t}^{*} f_{I, t}^{*}}{Z_{t}^{*}} .
\end{aligned}
$$

\footnotetext{
${ }^{11}$ Notice that this model assumes there is no per-period fixed cost of domestic production.
} 
The optimal profits for each firm, relative to the price index of the market in the headquarters' location, are expressed as follows:

$$
\begin{aligned}
\pi_{D, t}(\omega) & =\rho_{D, t}^{1-\sigma}(z ; \omega) \frac{C_{t}}{\sigma} \\
\pi_{I, t}(\omega) & =Q_{t}\left[\rho_{I, t}^{1-\sigma}(\omega) \frac{C_{t}^{*}}{\sigma}-\frac{w_{t}^{*} f_{I, t}^{*}}{Z_{t}^{*}}\right] .
\end{aligned}
$$

Combining profits from the two markets, the total operating profits for a firm producing variety $\omega$ can be defined as

$$
\pi_{t}(z)=\pi_{D, t}(\omega)\left[I_{D}\left(z_{\min } \leq z\right)\right]+\pi_{I, t}(\omega)\left[I_{I}\left(z_{I} \leq z\right)\right]
$$

where $I_{D}($.$) and I_{I}($.$) are indicator functions from which we can obtain the average profits,$ computed as the sum of the average profits from the domestic market and the average profit from affiliates' activities:

$$
\widetilde{\pi}_{t} \equiv \int_{z_{\min }}^{\infty} \pi_{t}(z) d G(z)+\int_{z_{I}}^{\infty} \pi_{t}(z) d G(z)
$$

This structure of profits reflects the fact that among a total mass of firms $N_{D, t}$ producing domestically in every period in each country, there are a total of $N_{D, t}$ domestic producers and $N_{I, t}^{*}=\left[1-G\left(z_{I}^{*}\right)\right] N_{D, t}^{*}$ foreign firms engaging in FDI at home, where $G(z)$ is a distribution with support $\left[z_{\min }, \infty\right)$. Average productivity levels are defined as in Melitz (2003), as I consider separately the average productivity of firms that produce and those that sell "only" domestically $\left(\widetilde{z}_{D}\right)$ and those that sell domestically and also engage in multinational production $\left(\widetilde{z}_{I}\right)$ :

$$
\widetilde{z}_{D, t} \equiv\left[\int_{z_{\min , t}}^{\infty} z_{t}^{\sigma-1} d G\left(z_{t}\right)\right]^{\frac{1}{\sigma-1}}, \quad \widetilde{z}_{I, t} \equiv\left[\frac{1}{1-G\left(z_{I, t}\right)} \int_{z_{I, t}}^{\infty} z_{t}^{\sigma-1} d G\left(z_{t}\right)\right]^{\frac{1}{\sigma-1}} .
$$

The weights of the averages are proportional to relative firm output shares and summarize all 
relevant information on the productivity distribution, as shown in Melitz (2003) 12 Another approach to obtaining these productivity averages is to observe that $\widetilde{\pi}_{D, t} \equiv \pi_{D, t}\left(\widetilde{z}_{D, t}\right)$ and $\widetilde{\pi}_{I, t} \equiv \pi_{I, t}\left(\widetilde{z}_{I, t}\right)$. Thus, $\widetilde{\pi}_{D, t}$ are the average firm profits from domestic sales, while $\widetilde{\pi}_{t} \equiv$ $\tilde{\pi}_{D, t}+\tilde{\pi}_{I, t}\left[1-G\left(z_{I, t}\right)\right]$ are total profits earned by the average firm at home.

I assume that productivity $z$ is distributed according to a Pareto $\left(z_{\min }, k\right)$ distribution 13 ,

$$
g(z)=\frac{k z_{\min }^{k}}{z^{k+1}} \quad G(z)=1-\left(\frac{z_{\min }}{z}\right)^{k} \quad k>\sigma-1 .
$$

Under Pareto productivity, the above-defined geometric averages become

$$
\widetilde{z}_{D, t}=\nabla^{\frac{1}{\sigma-1}} z_{\min , t}, \widetilde{z}_{I, t}=\nabla^{\frac{1}{\sigma-1}} z_{I, t} \quad \text { with } \nabla=\frac{k}{k-(\sigma-1)}
$$

where $z_{\min }$ and $z_{I}$ are cutoff points that identify the marginal firm for which profits are null in the domestic and foreign production activities, as follows:

$$
\pi_{I, t}\left(z_{I}\right)=0 \Longleftrightarrow z_{I}=\left(\frac{f_{I, t}^{*}}{C_{t}^{*}}\right)^{\frac{1}{\sigma-1}}\left(\frac{w_{t}^{*} \sigma}{Z_{t}^{*}}\right)^{\frac{\sigma}{\sigma-1}}\left(\frac{1}{\sigma-1}\right) .
$$

Firms with $z>z_{I}$ earn positive profits from multinational production; firms with $z<z_{I}$ do not become international firms. Optimal profits are denoted as

$$
\tilde{\pi}_{I, t}=(\nabla-1) \frac{Q_{t} w_{t}^{*} f_{I, t}^{*}}{Z_{t}^{*}} \quad \nabla=\frac{k}{k-(\sigma-1)}
$$

The existence of fix costs of engaging in multinational production is key to predicting selfselection of the most productive firms into those segments. Only the most productive firms can amortize the fixed costs and make non-negative profits. Increased profit opportunities, furthermore, lead to increased entry and labor demand, which boost real wages and force the least productive firms to exit.

\footnotetext{
${ }^{12}$ The $\widetilde{z}$ s are weighted averages of the productivity levels and are independent of the number of firms, while the weights reflect the relative output shares of firms with different productivity levels.

13 The Pareto distribution of the productivity parameter implies that the distribution of sales is also a Pareto distribution, a feature consistent with firm-level data (Helpman, Melitz, and Yeaple, 2004). The term $z_{\text {min }}$ denotes the lower bound of the distribution and $k>\sigma-1$ is the shape parameter.
} 
I assume that $f_{I}$ is measured in host economy labor instead of home economy labor, an assumption that is key in determining the crowding out of local firms and is more consistent with the data. While we know that MNFs transfer personnel between parents and subsidiaries, the evidence suggests that the share of expatriates used as inputs in the production of affiliates is small; Sauvant et al. (1993) report that the great majority of employees in affiliates of Japanese and American MNFs are indeed hired locally. In 1989, these shares were $3 \%$ for Japanese MNFs and $0.4 \%$ for U.S. MNFs. There are at least two alternative modeling choices that are not adopted in this paper. The first is to consider a combination of a host country fixed cost with a home country fixed cost in otherwise homogeneous labor in a Cobb-Douglas function. This assumption would deliver an impact of changes in multinational production at the extensive and intensive margins producing direct effects in both the home and the host labor markets. Alternatively, I could introduce an additional type of worker - for example, the model could have both high-skill and low-skill workers. This extension would transform the fixed cost of multinational production in a Cobb-Douglas function of the two types of labor with the high-skill labor hired in the home economy and transferred to the host economy (for example, engineers and management, responsible for the production of the affiliates). Even in the context of the model presented here, the idiosyncratic productivity parameter $z$ could be interpreted as incorporating both total idiosyncratic productivity and high-skill labor as an input and is essentially analogous to this extension.

Under the Pareto $\left(z_{\min }, k\right)$ assumption, $z_{I}=\nabla^{-\frac{1}{\sigma-1}} \widetilde{z}_{I}$ allows simplifying the relative number of FDI firms $N_{I} / N_{D}=\left[1-G\left(z_{I}\right)\right] N_{D} / N_{D}$ and $N_{I}^{*} / N_{D}=\left[1-G\left(z_{I}^{*}\right)\right] N_{D}^{*} / N_{D}$ to

$$
\begin{gathered}
\frac{N_{I, t}}{N_{D, t}}=\left(\frac{z_{\min , t}}{\widetilde{z}_{I, t}}\right)^{k} \nabla^{\frac{k}{\sigma-1}} \\
\frac{N_{I, t}^{*}}{N_{D, t}}=\left(\frac{z_{\min , t}}{\widetilde{z}_{I, t}^{*}}\right)^{k} \nabla^{\frac{k}{\sigma-1}} \frac{N_{D, t}^{*}}{N_{D, t}} .
\end{gathered}
$$

For simplicity, I have derived profits and averages for firms of the home country. Correspondingly, the foreign country host firms are characterized by $N_{D, t}^{*}, N_{I, t}^{*}, \pi_{t}^{*}, \pi_{I, t}^{*}, z_{D, t}^{*}, z_{I, t}^{*}, \widetilde{z}_{D, t}$, 
$\widetilde{z}_{I, t}^{*}, \widetilde{\pi}_{t}^{*}, \widetilde{\pi}_{I, t}^{*}$, and $\widetilde{v}_{t}^{*}$.

The fixed cost of multinational production considered in this paper is measured in units of local effective labor but can be interpreted as the theoretical counterpart of a broader set of country-specific measures that affect the ease of starting a foreign business. There is evidence of both large cross-country variation in the cost of starting a foreign business and of its time variation. The World Bank project "Investing Across Borders 2010" provides comparable country-level measures of the procedural burden that foreign companies face when entering a new host economy market. To understand the range and some of the sources of this variation, the World Bank project constructed the following comprehensive index of restrictions and two more specific measures: (i) The "ease of establishment index" evaluates the characteristics of the regulatory regimes for business start-up (Figure 2) .14 (ii) The measure "number of procedures" covers the number of procedural steps involved in establishing a wholly foreign-owned subsidiary, both pre- and post-incorporation. (iii) The measure "time (days)" measures the number of days needed for each of the procedural steps required to establish a subsidiary of a foreign company (Figure 3). Figure 2 shows the first indicator as a histogram for the 96 countries available in 2010, and Figure 3 shows the other two indicators in a scatter diagram. The striking feature of these indicators is the large cross-sectional dispersion that can be interpreted as a counterpart of the dispersion of the level of $f_{I}$ in this model. As these measures are reported for 2010, the World Bank dataset does not allow tracing their evolution over time, but it still provides support for the notion that they may change over time as a country removes its restrictions to affiliates of MNFs. These measures include any change in regulation that reduces the extra burden carried by foreigners to register a business, remove limits to the composition of the board of directors of affiliate firms, or increase the availability of electronic documents (online laws, regulations, documents, and registration). These changes occur frequently and are relevant to determine

\footnotetext{
${ }^{14}$ The index focuses on the following areas: (i) restrictions on the composition of the board of directors or appointment of managers, (ii) requirements forcing the use of a local third party (counsel, notary, investment promotion agency) during the establishment process, (iii) availability of fast-track procedure, (iv) requirement of an investment approval, (v) business registration process, (vi) restrictions on holding a foreign currency bank account, (vii) minimum capital requirements, (viii) availability of electronic services for registration.
} 
the business environment of a country: For example, UNCTAD (2011) recorded 40 more favorable and 16 fewer unfavorable changes to entry and establishment regulation of affiliates, and 35 changes in promotion and facilitation of FDI ${ }^{15}$ Changes in $f_{I}$ in the model can be related to the relaxation of constraints to multinational production either decided unilaterally by countries or embedded in various multilateral or bilateral treaties. The World Trade Organization (WTO), for example, manages the Agreement on Trade-Related Investment Measures (TRIMs Agreement), one of the multilateral agreements on trade in goods that prohibits trade-related investment measures, such as local content requirements, that are inconsistent with basic provisions of the 1994 General Agreement on Tariffs and Trade. The General Agreement on Trade in Services allows commitments by individual countries to remove barriers to foreign entry in the services sector in the portion regulating the supply of services via establishment/commercial presence (so-called mode 3). Since the timing and magnitude of the removal of these barriers are promises contained in the Schedule of Commitments, they can be interpreted as changes in the fixed cost of multinational production at the country level ${ }^{16}$ In addition, various provisions of the Mercosur treaty, the NAFTA treaty, as well as various elements contributing to free capital movement in the European Union treaties, essentially removed barriers to FDI among member countries through mechanisms that can be interpreted as a reduction of $f_{I}$ in the context of our model.

[Figures 2 and 3 here]

\section{Current Account and Labor Market}

Under the assumption of financial autarky,i $B_{t}^{H}=B_{t+1}^{H}$ and $x_{t}=x_{t+1}=1$. This assumption and the absence of exports and unilateral transfers, implies that the current account reduces to the net repatriation of profits from multinational activities $N_{I} \widetilde{\pi}_{I, t}-Q_{t} N_{I}^{*} \widetilde{\pi}_{I, t}^{*}=0$, where

\footnotetext{
${ }^{15}$ These counts refer to the countries surveyed in the Investment Policy Monitor database and only to 2010.

${ }^{16}$ The WTO has also-so far unsuccessfully-promoted negotiations to reach a Multilateral Agreement on Investment designed to lower barriers to FDI on a multilateral basis in manufacturing industries.
} 
$\widetilde{\pi}_{I, t}$ are real profits (nominal profits $\widetilde{\Pi}_{I, t}$ divided by the price index in the location of the parent $P_{t}$ ) made in the foreign country by the parent, and measured in home currency. $\widetilde{\pi}_{I, t}^{*}$ are real profits (nominal profits $\widetilde{\Pi}_{I, t}^{*}$ divided by the price index in the location of the foreign company $\left.P_{t}^{*}\right)$ made in the home country by the foreign company, and measured in foreign currency. Hence, the real exchange rate (RER) works as a clearing mechanism for the differential in profits from multinational activity as in Lubik and Russ (2012): $Q_{t}=N_{I} \widetilde{\pi}_{I, t} / N_{I}^{*} \widetilde{\pi}_{I, t}^{*}$.

As for the labor markets, new entrants in the home country hire $f_{E, t}$ workers as an entry cost, while each home producer that engages in multinational production hires $f_{I, t}^{*}$ foreign workers per period to cover the fixed cost of multinational production. At the same time, each foreign firm producing domestically hires $f_{I, t}$ domestic workers per period to carry out multinational production in the home country.

Sales at home generate profits for home firms with idiosyncratic productivity $z$ and profits for foreign-owned affiliates with idiosyncratic productivity $z^{*}$ according to

$$
\begin{aligned}
\pi_{D, t}(z) & =\frac{1}{\sigma-1} w_{t} l_{D, t}(z) \\
\pi_{I, t}^{*}(z) & =\frac{1}{Q_{t}}\left(\frac{1}{\sigma-1} w_{t} l_{I, t}\left(z^{*}\right)-w_{t} \frac{f_{I}}{Z_{t}}\right) .
\end{aligned}
$$

Notice that foreign firms that hire labor in the domestic country pay the domestic wage rate, but at the same time the foreign firms transfer their idiosyncratic technology $\left(z^{*}\right)$ to the home country. From the optimal profits above, I can derive the average amount of labor hired to cover domestic sales and FDI sales of the average foreign firm, to which I can add the "investment" labor hired by new entrants $N_{E, t} f_{E, t} / Z_{t}$ to obtain the total home labor demand:

$$
L_{t}^{D}=(\sigma-1) N_{D, t}\left[\frac{\widetilde{\pi}_{D, t}}{w_{t}}\right]+(\sigma-1) N_{I, t}^{*} \frac{Q_{t} \widetilde{\pi}_{I, t}^{*}}{w_{t}}++\frac{N_{E, t} f_{E, t}}{Z_{t}}+\sigma N_{I, t}^{*} \frac{f_{I, t}}{Z_{t}} .
$$

Since the labor supply is fixed at $L_{t}^{S}=w_{t}^{\frac{1}{x-1}}$, equilibrium is such that wages are determined endogenously as follows: 


$$
w_{t}^{\frac{1}{\chi-1}}=\frac{1}{w_{t}}(\sigma-1) N_{D, t} \widetilde{\pi}_{D, t}+\frac{1}{w_{t}}(\sigma-1) N_{I, t}^{*} Q_{t} \widetilde{\pi}_{I, t}^{*}+\frac{N_{E, t} f_{E, t}}{Z_{t}}+\sigma N_{I, t}^{*} \frac{f_{I, t}}{Z_{t}} .
$$

\section{System Dynamics}

There are 27 endogenous variables. Of these, 17 are not predetermined at $t: w_{t}, w_{t}^{*}, \widetilde{\pi}_{t}$, $\tilde{\pi}_{t}^{*}, N_{E, t}, N_{E, t}^{*}, N_{I, t}, N_{I, t}^{*}, \widetilde{z}_{I, t}, \widetilde{z}_{I, t}^{*}, \widetilde{v}_{t}, \widetilde{v}_{t}^{*}, C_{t}, C_{t}^{*}, L_{t}, L_{t}^{*}$, and $Q_{t} ; 4$ are predetermined at $t$ : $N_{D, t}, N_{D, t}^{*}, r_{t}$, and $r_{t}^{*}$; there are 6 endogenous expectational errors: $\eta_{t}^{\widetilde{v}}, \eta_{t}^{\widetilde{v}^{*}}, \eta_{t}^{\widetilde{\pi}}, \eta_{t}^{\widetilde{\pi}^{*}}, \eta_{t}^{C}$, and $\eta_{t}^{C^{*}}$. The systems are log-linearized around the steady-state, represented in canonical form as $\Gamma^{0} \hat{y}_{t}=\Gamma^{1} \hat{y}_{t-1}+\Psi \hat{z}_{t}+\Pi \eta_{t}$ and solved using the Gensys algorithm.

\subsection{Calibration}

Parameters are chosen to provide a term of comparison with the results in Ghironi and Melitz (2005) that focuses on endogenous tradedness (Table 1).

[Tables 1 and 2 here]

The values of the discount factor to simulate annual data $(\beta)$, the elasticity of substitution between consumption and hours $(\chi)$, and the coefficient of relative risk aversion $(\gamma)$ are standard in the literature. The values of $\sigma$ and $k$ determine the dispersion of firms' sales under the Pareto assumption; $\sigma=3.8$ implies a mark-up of $\mu=35 \%$ that captures a component over average fixed costs. Without loss of generality I assume the lower bound of the Pareto distribution $z_{\min }$ to be 1 . The two countries are identical, so the same parameters apply to both.

The steady-state values of key variables are listed in Table 2 . The ratio of new to existing varieties $\frac{N_{E}}{N_{D}}$ is calibrated to be smaller than the ratio of job destruction for the United States (10\%). The share of domestic producers and affiliates over the total number of firms depends on the fixed cost of multinational production $f_{I}$, which I can change as other exogenous 
variables, but I assume to be equal to the annualized fixed cost of entering production for a new variety present discounted value $P D V\left(f_{E}\right)$ in the benchmark calibration that I use to plot the impulse-response functions. Higher values of $f_{I}$ reduce the share of MNFs as the multinational entry cutoff productivity level shifts upward. I experimented with different levels of the fixed cost of entry and the qualitative response of the model remained similar, as did the uniqueness and determinacy of the linear rational expectation system. The ranking of the average productivity levels also depends on the cutoff point. Under the benchmark calibration, the average firm in each economy is $86 \%$ more productive than the most unproductive non-exiter. The average local firm, however, is only $18 \%$ more productive. As for MNFs, the marginal MNFs (at the cutoff point that defines the extensive margin) is approximately $50 \%$ more productive than the average firm in the economy, a value that is consistent with the estimates in firm-level data in Helpman, Melitz, and Yeaple (2004) ${ }^{17}$ Because there is a negative relationship between idiosyncratic prices and productivity, the average price rankings are reversed, with relatively less productive local producers charging relatively higher prices.

As for aggregate variables, consumption composes approximately $90 \%$ of GDP, while investment to finance the entry of new firms absorbs approximately $10 \%$ of the aggregate output ( $15 \%$ to $20 \%$ in the average OECD country).

\subsection{Impulse-Response Functions}

I plot impulse-response functions to show the dynamic behavior of this stylized economy. Figures 4 through 8 focus on the case of financial autarky and represent the dynamic responses of the main variables of the economy to a $+1 \%$ temporary cross-sectional productivity $(Z)$

\footnotetext{
${ }^{17}$ An alternative calibration would have the steady-state level of the model calibrated based on the number of U.S. firms that are MNFs. In the model I develop, firms, products, and plants are essentially indistinguishable. In reality, U.S. MNFs, in addition to being large, are multiproduct firms. The number of U.S. firms that are MNFs is a tiny fraction of the number of U.S. firms and would return a counterfactually low share of multinational production in the host economy. The current calibration is a more accurate description of the actual structure of production based on ownership. It should also be noted that the basic logic of the model applies independently of the variable chosen for the calibration (share of affiliates or share of multinational production).
} 
shock in the home economy and a $-1 \%$ reduction of the fixed costs of entry $\left(f_{E}\right)$ and the fixed cost of affiliate production $\left(f_{I}\right)$. All shocks are common across firms and all variables referring to profits, prices, and idiosyncratic productivity should be read as averages (with tilde).

Temporary aggregate Productivity increases. Figure 4 plots the case of a temporary aggregate productivity increase in the home country. On impact, while $Z_{t}$ increases by 1 percent, the home market temporarily becomes a relatively more attractive business environment. Higher aggregate productivity reduces the fixed cost of entering for domestic firms $\left(w_{t} f_{E, t} / Z_{t}^{*}\right)$ so that the number of entrants at home $N_{E}$ jumps on impact, which triggers the entry of producers in the following periods. The positive common technology shock reduces the annualized cost of producing in the home market for foreign firms $\left(w_{t} f_{I, t} / Z_{t}\right)$. The number of foreign affiliates at home $N_{I}^{*}$ increases temporarily. The new multinational production output would have generated no profits before the increase of aggregate productivity, as its associated idiosyncratic productivity was too low; after the aggregate productivity shock, the new marginal multinational plant has lower idiosyncratic productivity. The cutoff productivity level $z_{I}$ and the weighted average productivity of MNFs $\tilde{z}_{I}$ both drop on impact. Entry increases labor demand, so home labor costs $w$ increase. The entry of less efficient foreign producers increases the average price charged by foreign affiliates in the home country $\left(\hat{\rho}_{I}^{*}\right)$. The average price charged by domestic firms $\hat{\rho}_{D}$ also increases, so the overall aggregate price index at home $P=\left[N_{D} \widetilde{p}_{D}{ }^{1-\sigma}+N_{I}^{*} \widetilde{p}_{I}^{1-\sigma}\right]^{\frac{1}{\sigma-1}}$ increases (more than in $P^{*}$ ). This explains why the real exchange rate jumps, as well. In addition, we observe an increase in the relative cost of labor adjusted for productivity, here labeled as terms of labor $\left(T O L_{t}\right)$ and defined as $T O L_{t} \equiv\left(e_{t} \frac{W_{t}^{*}}{Z_{t}^{*}}\right) /\left(\frac{W_{t}}{Z_{t}}\right)$. Increased productivity translates into lower operating costs and higher profits; hence, $\hat{\pi}_{D}$ increases. Weighted average profits fall for foreign affiliates $\left(\hat{\pi}_{I}\right)$, however, because entrants in the home economy are less efficient and hence less profitable.

However, the home market is not a permanently more attractive business environment; as the productivity mean-reverts, the number of entrants $N_{E}$, as well as the (lagged) number of producers $N_{D}$, begins to decrease. The existence of fewer firms weakens the demand for 
workers, which in turn causes a decline in wages - after impact - toward the long-run equilibrium. Both $z_{I}^{*}$ and $N_{I}^{*}$ return to the steady-state level, along a hump-shaped curve due to the wage response to the temporary productivity shock, which induces the entry of MNFs' affiliates. In the transition dynamics, the relative increase in home wages determines some readjustment: The increases in $\widetilde{\rho}_{I}$ and $\widetilde{\rho}_{I}^{*}$ are totally reabsorbed during the transitional period; the reduction in $\widetilde{\rho}_{I}$ is due to the exit of the least productive firms in the pool of $N_{I}^{*}$. After impact, the RER undershoots, following the relative price indices and eventually reverts to the steady-state level; the TOL follow a similar adjustment.

[Figure 4 here]

Permanent aggregate Productivity increases. When the aggregate productivity increase of $+1 \%$ in the home economy is permanent, we observe impulse-response graphs similar to those in Figure 5. The home market permanently becomes a relatively more attractive location. This reduces the fixed cost of home market entry for domestic firms, $w_{t} f_{E, t} / Z_{t}$. The number of entrants at home $N_{E}$ jumps on impact and triggers the entry of producers in the following period. The positive common technology shock reduces the annualized costs incurred by foreign firms to produce in the home market $\left(w_{t} f_{I, t} / Z_{t}\right)$ since such costs are also measured in units of effective labor. The number of foreign multinational producers at home $N_{I}^{*}$ increases permanently. In fact, the cutoff productivity level for multinational production $z_{I}^{*}$ and weighted average $\tilde{z}_{I}^{*}$ drop on impact and remain permanently lower. The entry of less productive foreign producers pushes up the average prices charged by affiliate firms $\hat{\rho}_{I}^{*}$. Increased productivity translates into lower operating costs and higher profits. Hence, $\hat{\pi}_{D}$ increases. Weighted average profits of affiliates $\hat{\pi}_{I}^{*}$ fall because entrants at home are less productive and hence less profitable.

In the new steady state, the home market is a relatively more attractive business environment. Higher aggregate productivity draws a permanently higher number of entrants $N_{E}$, which translates into a permanently higher number of producers $N_{D}$. For both $z_{I}^{*}$ and $N_{I}^{*}$, the impact effect is larger than the long-run effect because the dynamic behavior of labor 
costs counterbalances the initial jump: While wages increase, fewer MNFs find it profitable to enter. Hence, $z_{I}^{*}$ increases and $N_{I}^{*}$ decreases during the transitional dynamics. During the transition, the relative increase of home wages determines some readjustment: The $\widetilde{\rho}_{I}$ and $\widetilde{\rho}_{I}^{*}$ increases are partially reabsorbed in the transitional period; the reduction of $\widetilde{\rho}_{I}$ caused by the exit of the least productive firms in the pool of $N_{I}^{*}$ is more than compensated by the increase in wages that translates, in turn, to higher prices.

[Figure 5 here]

Permanent Reduction of $f_{E}$ In the home economy (Figure 6). On impact, $f_{E}$ decreases by 1 percent. This reduces the fixed cost to enter the home market for domestic firms $\left(w_{t} f_{E, t} / Z_{t}\right)$. The number of entrants at home $N_{E}$ jumps on impact and this triggers the entry of producers $N_{D}$ in the following periods. In the long run, the home market remains a relatively more attractive business environment for the pool of potential home entrants that draw their idiosyncratic productivity level from the same distribution with support $\left[z_{\min }, \infty\right)$. However, in the first period, the investment cost is financed by lower current consumption, so $C$ falls on impact. A large number of domestic entrants increases labor demand, so the home labor costs $w$ increase. For foreign firms, the annualized cost to produce in the home market $\left(w_{t} f_{I, t} / Z_{t}\right)$ does not change; however, the drop in home expenditures reduces the home sales of foreign affiliates and induces some exit. The number of foreign affiliates at home $N_{I}^{*}$ decreases on impact, while the multinational cutoff productivity level $z_{I}^{*}$ and weighted average $\tilde{z}_{I}^{*}$ jump up. The exit of less productive foreign producers lowers the average prices charged by affiliates $\hat{\rho}_{I}^{*}$. The weighted average profits of FDI $\hat{\pi}_{I}^{*}$ increase, however, because the pool of remaining affiliates at home is both larger and more productive - and hence more profitable. The increase in home wages continues to push foreign firms out $\left(N_{I}^{*}\right.$ continues to decrease after the initial drop). The present discounted value of the stream of future profits transferrable to the foreign economy, however, increases because the remaining affiliates earn higher profits, reversing the initial drop of $N_{E}^{*}$ over time. $N_{D}^{*}$, which falls after the shock, starts growing, eventually leading to a higher long-run level of $N_{D}^{*}$. 
As for home prices, relatively less productive domestic entrants boost $\hat{\rho}_{D}$ while the average price charged by remaining survivors $\left(\hat{\rho}_{I}^{*}\right)$ starts growing again as wages rise. As for foreign prices, transitional positive entry increases $\hat{\rho}_{D}^{*}$, while the average price $\hat{\rho}_{I}$ charged by home affiliates in the foreign country changes very little, which makes aggregate prices grow

over time as $P=\left[N_{D} \widetilde{p}_{D}^{1-\sigma}+N_{I}^{*} \widetilde{p}_{I}^{* 1-\sigma}\right]^{\frac{1}{\sigma-1}}$. Home prices increase more than foreign prices and the real exchange rate $q_{t}$ appreciates.

[Figure 6 here]

\section{$5 \quad$ Entry and Aggregate Productivity}

This section focuses on the relationship among multinational presence, measured productivity, and growth. Since the model is nonlinear and contains a large number of endogenous variables, the relationship between exogenous variables (fixed costs and aggregate productivity) and endogenous variables (measured productivity and output, for example) can only be shown numerically and not by using formal mathematical proofs. To discuss the impact of entry on productivity and output, I first study the effects of a reduction of $f_{I}$ in the home and the foreign economy resulting, for example, from an agreement to reduce the extra burden required to set up an affiliate. I use two stylized graphs to show how such a shock qualitatively affects the composition of the producers in the home country (Figure 7) and discuss impulse-response graphs (Figure 8). I then compute and discuss various steady states corresponding to different levels of the fixed costs of multinational production (Figure 9) that help me establish the relationship among $f_{I}$, measured productivity, and measured output. Finally, I show the dynamic response of the model to a temporary aggregate productivity shock under different scenarios mirroring selected levels of $f_{I}$ (Figure 11) and discuss the empirical implications of these results. 


\subsection{Impulse-Response Functions Analysis}

To discuss the impact of entry on productivity consider the case of a permanent reduction of $f_{I}$ in the home and the foreign economy resulting, for example, in an agreement to reduce the extra burden required to set up an affiliate. In the model, MNFs initially respond to this shock at the extensive margin as the lower fixed cost of entry attracts new affiliates in the host economy, hence adding their production to the output of the existing firms. Increased entry, however, boosts the country-wide demand for labor and wages increase production costs for both existing affiliates and existing domestic firms.

[Figures 7 and 8 here]

Figure 7 shows the impact of the reduction of $f_{I}$. The top diagram depicts the relationship between idiosyncratic productivity and operating profits. For low levels of $z$, the operating profits are too small to compensate for the fixed cost of producing through affiliates $\left(w_{t} f_{I, t} / Z_{t}\right)$; therefore, foreign firms will produce only in the foreign economy. The larger the idiosyncratic productivity, the larger are operating profits. Any firm with idiosyncratic productivity larger than the cutoff point $z_{I}^{*}$ earns positive total profits from adding foreign production to its domestic capabilities. The intercept of the profit curve is affected by three factors determined in the home economy: the fixed cost of producing through affiliates, the wage rate, and the aggregate productivity. When $f_{I}$ lowers, the profit curve shifts up and the cutoff point for multinational production moves to the left so that a larger share of the population of foreign firms engages in production through foreign affiliates, as depicted in the bottom diagram of Figure 7. Now consider Figure 8, which plots the dynamic response to a $1 \%$ decrease in $f_{I}$, which amounts to a reduction of the fixed cost to enter the home market for foreign firms $\left(w_{t} f_{I, t} / Z_{t}\right)$. The number of affiliates in home $N_{I}^{*}$ jumps on impact, while the foreign affiliates' cutoff productivity level $z_{I}^{*}$ and weighted average $\tilde{z}_{I}^{*}$ also drop. Demand for labor increases, so that the home wages $(w)$ increase on impact, labor income $(w L)$ increases, and consumption increases permanently. Higher expected future sales trigger domestic entry $\left(N_{E}\right)$, which has a positive impact on the number of producers. Increased production appre- 
ciates the wage rate during the transition. Entry of less productive foreign producers boosts the average prices charged by affiliates $\left(\hat{\rho}_{I}^{*}\right)$, and the weighted average profits of affiliates $\hat{\pi}_{I}^{*}$ decrease because the pool of remaining foreign affiliates at home is less productive - and hence less profitable.

\subsection{The Steady-State Relationship between Multinationals' Pres- ence, Productivity and Output}

In this simple model, the incremental entry of relatively less productive firms reduces the average productivity of the multinational sector in the economy. In this environment, a larger multinational presence occurs at the same time as the average productivity of these affiliates decreases. Hence, while countries with increasing stocks of FDI are expected to grow faster, the contribution of the multinational affiliates to the host countries' productivity level and output decreases with an increased foreign presence and larger multinational entry does not necessarily translate into a larger benefit for the host country. One way to observe this effect in the economy at large is to consider a measure of observed average productivity that decomposes country-wide weighted productivity into a component related to foreign affiliates and a component attributed to domestic producers, as follows:

$$
\widetilde{Z}_{t}=\frac{N_{D, t}}{N_{D, t}+N_{I, t}^{*}} \widetilde{z}_{D, t} Z_{t}+\frac{N_{I, t}^{*}}{N_{D, t}+N_{I, t}^{*}} \widetilde{z}_{I, t}^{*} Z_{t}
$$

[Figures 9 and 10 here]

where $\widetilde{z}_{D, t} Z_{t}$ and $\widetilde{z}_{I, t}^{*} Z_{t}$ are only determined by exogenous parameters when $Z_{t}=1$ in the steady state, but can otherwise fluctuate with $Z_{t}$ when it fluctuates as the system is shocked out of the steady state.

However, I can show that measured productivity of affiliates decreases with entry and how

this reduces the economy-wide measured productivity $\left(\widetilde{Z}_{t}\right)$ and output $\left(\widetilde{y}_{t}\right)$. It should be noted that the analysis in this subsection abstracts from either temporary or aggregates shocks to productivity and focuses simply on the steady state. The solution to the steady states is 
discussed in Appendix C. Equation (C.23) can be solved numerically to obtain $\widetilde{z}_{I}$ and the remaining endogenous variables can be obtained using the computed value of $\widetilde{z}_{I}$. Therefore, I can calculate and plot the steady-state level of $\widetilde{z}_{I}$ and other endogenous variables for different values of the exogenous variable $f_{I}$; the interpretation of this relationship is that the average measured productivity of the affiliates in various countries depends on the magnitude of multinational production, which in turn is determined by the fixed cost of multinational production 18 The left plot in Figure 9 shows clearly that the average measured productivity of the affiliates located in the home country decreases with decreases in $f_{I}$ (at an increasing rate) owing to the concavity of the relationship established by equation (C.23), confirming the intuition provided in Figure 7. What effect does lower $f_{I}$ have on country-wide measured productivity and output? For each level of $f_{I}$, I can compute the steady-state level of endogenous variables and provide a graphical representation that amounts to a comparative static exercise. The relationship between $f_{I}$ and $\widetilde{Z}$ is more complex because of the general equilibrium structure of the model: Lower fixed costs of multinational production attract affiliates and drive labor costs up for all firms in the economy; this in turn crowds out local firms and affects measured productivity. The ratio of foreign to domestic producers increases (as shown in the center plot in Figure 9) as more affiliates locate in the home economy, so the larger share of affiliates counterbalances the lower average productivity (right plot in Figure 9). The left plot in Figure 9 shows the relationship between multinational presence and measured productivity is non-monotonic. Reductions of $f_{I}$ mildly increase measured average productivity in the home economy above a certain threshold of $f_{I}$ and reduce it sharply below it. Three facts should be noted: First, the specific point where the relationship between $f_{I}$ and $\widetilde{Z}$ switches from negative to positive is defined by the value of the other parameters chosen to calibrate the model; therefore, the maximum of the curve could be to the right or the left relative to the plot depending on other parameters values. Changing these particular parameters would also move the maximum to the left or to the right relative to the current

\footnotetext{
${ }^{18}$ I totally differentiated Equation (C.23) and numerically calculated the derivative of $\widetilde{z}_{I}$ with respect to $f_{I}$ and verified that it is monotonically decreasing in $f_{I}$ for $f_{I}>0$.
} 
plot (as well as make the curve more or less concave) in the second graph of Figure 9. Second, here I chose levels of $f_{I}$ and other parameters that provide a reasonable calibration consistent with the data but also guarantee determinacy and uniqueness of the linear rational expectation models. For a contour of the values chosen in the benchmark calibration, the model is always unique and is not characterized by indeterminacy. Figure 9, however, plots steady-state values of the endogenous variables and therefore is not limited to solutions of the rational expectations system that are unique. Therefore, changing other parameters used in the calibration may alter the determinacy and uniqueness properties of the linear rational expectations model. Finally, the slope of the curve at different values of the proxy for multinational presence is related to the slope of the underlying productivity distribution.

As discussed in the introduction, researchers using aggregate data without controlling for the composition effect just described often estimate equations similar to the following:

$$
Y_{j}=\alpha+\beta_{0} * F D I_{j}+\beta_{1}\left(F D I_{j} * x_{j}\right)+\gamma X_{j}+\epsilon_{j}
$$

in which $F D I_{j}$ is a measure of the presence of MNFs and other variables are as defined in the introduction $[9$ Consider the number of affiliates of MNFs as a share of total producers in an economy $\left[N_{I}^{*} /\left(N_{I}^{*}+N_{D}\right)\right]$. This is one possible measure of multinational presence in a country. The comparative static exercise based on the calibrated steady states just described allows the definition of a relationship between this measure and measured output $(\tilde{y})$. Consider Figure 10. Assume that instead of representing a specific steady state, each square represents a country with a certain fixed cost of multinational production determining a certain level of multinational presence $\left[N_{I}^{*} /\left(N_{I}^{*}+N_{D}\right)\right]$. Then the relationship between $N_{I}^{*} /\left(N_{I}^{*}+N_{D}\right)$ and $(\tilde{y})$ is akin to the relationship estimated in the above regression. Although a formal proof of this relationship cannot be provided in this context, the computational exercise shows clearly that the relationship is (similar to the relationship between $f_{I}$ and $\tilde{Z}$ ) non-monotonic and can induce the type of results reported in the empirical literature: failure to establish a positive

\footnotetext{
${ }^{19}$ If the equation is estimated in levels, it contains the stock of FDI and the level of GDP; if it estimated in first differences, it relates GDP growth to FDI flows.
} 
relationship between FDI and the level of output or growth. While the left graph represents all countries, the center plot shows that the relationship is positive for countries with a small multinational presence $\left(\hat{\beta}_{0}>0\right)$, whereas the relationship is negative for countries with many affiliates. When countries are pooled, the relationship depends on the frequency of countries hosting more affiliates relative to the frequency of countries hosting fewer affiliates. In the left plot this relationship is negative. This result echoes the worries of Bloningen and Wang (2005), who argue that the pooling of countries characterized by different levels of development - and presumably of multinational presence - should be done carefully in empirical FDI studies. Bloningen and Wang (2005) also report that (i) the effect of FDI on economic growth is one that is supported only for less developed countries in the aggregate data, not developed countries, and (ii) the evidence suggests that FDI is much less likely to crowd out (more likely to crowd in) domestic investment for less developed countries than developed countries. The calibrated model and its implications shown in Figure 10 provide one possible explanation for this result.

\subsection{The Interaction Between Productivity Shocks and the Cost of Multinational Production}

The model allows tracing the relationship between the entry of MNFs and various endogenous variables. In particular, it shows how changes in the impact of aggregate productivity shocks on measured productivity are dependent on the presence of a large or small share of affiliates in the population of firms in the host economy. Notice that, as evident from the right graph in Figure 9, and in the left graph in Figure 10 there is a mapping close to one between measured productivity and measured output. In growth-FDI regressions, this relationship is estimated regressing GDP growth on the stock of FDI with mixed efforts in trying to control for the fact that the share of multinational firms and measured productivity and output, as well as their growth, are jointly determined in general equilibrium. As in the previous subsections, this analysis must rely on numerical exercises. Figure 11 shows the 
response to a temporary aggregate productivity increase in the home country (left graph) on the average (measured) productivity of foreign affiliates in the home economy $\left(\tilde{z}_{t, I}^{*}\right)$ and on the measure of country-wide average productivity $\left(\tilde{Z}_{t}\right)$ in three cases in which the fixed cost of multinational production $f_{I}$ is $20 \%$ (second graph), $100 \%$ (third graph), and 10 times the present discounted value of the fixed cost of entry $f_{E}$ (fourth graph). The interaction between the fixed cost of multinational production and the slope of the productivity distribution (governed by the parameter $k$ ) determines the share of foreign firms engaging in multinational production. The smaller this cost, the larger the share of foreign firms engaging in multinational production and the larger the number of affiliates as a share of total producers in the home economy. As the share of foreign affiliates in the home country increases, the affiliates' average productivity decreases; therefore, the change in the measure of country-wide average productivity depends crucially on the interaction of $N_{I, t}^{*}$ and $\widetilde{z}_{I, t}^{*}$. The graphs show clearly that small fixed costs attract so many relatively less productive foreign MNFs that average productivity may actually fall in response to an aggregate productivity shock.

\section{[Figure 11}

The most relevant implication of this result is that while we conjecture that countries with an increasing multinational presence should grow faster when, for example, they receive a positive aggregate productivity shock, the contribution of their presence to the host countries' average productivity level and output — and therefore their growth — decreases. This seemingly counterintuitive relationship hinges on the relationship between multinational status and idiosyncratic productivity, which is supported by robust microeconomic evidence. In cross-country or panel studies that estimate models similar to the one discussed in the introduction $\left(\dot{Y}_{j}=\alpha+\beta_{0} * F D I_{j}+\beta_{1}\left(F D I_{j} * x_{j}\right)+\gamma X_{j}+\epsilon_{j}\right)$, this confounding relationship could contribute to explaining the difficulties in finding positive significant $\beta_{0}$ coefficients, in addition to the non-monotonic relationship between FDI and output discussed in subsection 5.2 . 
Finally, this analysis raises an issue also brought to light by Russ's(2007) study of the endogeneity of exchange rate as a determinant of FDI: The general equilibrium structure of the model shows that because multinational presence, measured productivity, and output are jointly determined, growth regressions suffer from important endogeneity problems.

\subsection{The Implications for the Empirical Literature on FDI and Growth}

As the previous sections discussed, the empirical literature uses various measures of FDI in a country. Some papers consider the stock of FDI; some papers use annual flows, or the sum of flows over a certain number of years. This model uses neither physical capital per se nor investment but is developed using variables that can be treated as proxies for capital and investment. The number of firms producing in each country under domestic or foreign ownership can be interpreted as a measure of the capital stock (see, for example, Ghironi and Melitz, 2005). As the lowering of the fixed cost of multinational production (or the increase of domestic aggregate productivity) induces marginal entrants to engage in multinational production, the new producers $\left(N_{I, t}-N_{I, t-1}\right)$ - proxied by FDI flows - have lower productivity than the existing stock of affiliates - proxied by the FDI stock. As these new entrants enter the pool of affiliates, the stock of affiliates $\left(N_{I, t}\right)$ also displays lower average productivity. Therefore, if the interpretation of the number of firms as capital stock (partially owned domestically and partially owned by foreign firms) is accepted, it follows that additional affiliates reduce the contribution of FDI to the measured productivity of the host country (as seen in subsection 5.2) and productivity growth (as seen in subsection 5.3). The empirical literature thus faces a difficult task of distinguishing between the effect of macroeconomic developments and the composition of the firms' population when it tries to estimate the effect of FDI on growth. Recent developments in empirical industrial organization have paved the way to reconstruct aggregate productivity from firm- or plant-level data (see, for example, Rodrigue, 2010). Moreover, the use of a structural estimation approach similar to 
the recent work of Eaton, Kortum, Neiman, and Romalis (2011) may allow researchers to exploit the connection between dynamic models of FDI in general equilibrium and the data.

\section{Conclusions}

Most of the existing theoretical literature favors the idea that the entry and production of MNFs contribute positively to the productivity level and growth of host economies, but theoretical and empirical work has not established why this contribution is difficult to identify in cross-country and panel regressions (Harrison and Rodriguez-Clare, 2010). In this paper, I examined two conflicting mechanisms by which multinational production affects the welfare of the host economy when firms are heterogeneous in productivity: contribution to productivity growth due to technology transfer and entry/exit and their effect of aggregate productivity due to the combination of fixed costs of production and sorting of entrants. I argued that these mechanisms can reconcile the microeconomic evidence of superior idiosyncratic productivity of MNFs and their affiliates with the lack of aggregate evidence on the relationship between multinational production and growth.

I showed that if firms incur a fixed cost to become MNFs and this cost decreases either because of FDI liberalization or increased attractiveness of foreign markets, then entrants sort according to their own productivity. The most productive firms become MNFs earlier, whereas firms that are relatively less productive enter host economies later, consistent with micro evidence. The entry of relatively less productive firms then reduces the average productivity of the multinational sector in the host economy, which is coincident with the increase in the number of affiliates. Hence, countries with a larger multinational presence may experience a decreasing contribution of the affiliates' output to the host countries' productivity level and growth because of composition effects. Thus, larger multinational entry does not necessarily translate into a larger benefit for the host country because of the decreasing rate of productivity contribution and the boost in labor demand as the result of entry, which in turn penalizes existing domestic firms through increases in the cost of labor in general 
equilibrium.

One consequence of this analysis is that the empirical researcher measuring flows and stocks of FDI and running growth regressions faces the difficult task of controlling for the large heterogeneity of affiliates, in addition to other known problems of cross-country regressions. Future empirical work may try to control for these elements by reconstructing aggregate productivity from the bottom (firm- or plant-level) up, as suggested by Petrin and Levinsohn (2012), Petrin, White, and Reiter (2011), and Rodrigue (2014). A second consequence is that - even abstracting from the effects of cyclical movements in the host economy on the extensive margin of multinational production - the relationship between multinational presence and measured output is non-monotonic. Pooling countries with different levels of multinational production contributes to the weak empirical evidence on the relationship between FDI and output growth. For individual countries, as they move from having a handful of affiliates to having a large presence, the relationship between multinational presence and measured productivity and output changes from positive to negative. A third consequence is that both cyclical factors and structural factors affect the measures of multinational production and FDI observed in international data, in addition to differences in the presence of multinational affiliates. The previous section shows that a permanent reduction of the fixed cost of multinational production produces effects similar to a temporary reduction of aggregate productivity in the short term but different effects over the long term. These exercises show that traditional growth regressions likely capture both elements and with potentially conflicting effects on the sign of the estimated coefficients. Although - perhaps not surprisingly - it is extremely difficult to disentangle cyclical effects from steady-state differences in empirical work, the model suggests one possible explanation for the lack of robust evidence. Another avenue for future research may be to venture to a structural estimation exercise similar to the work of Eaton et al. (2011) in the context of the determinants of the Great Trade Collapse.

Finally, the model abstracts from international trade, resource-seeking vertical FDI, and export-platform FDI. The first two elements are developed in Zlate (2008) and Zlate (2010) 
with a focus on offshoring, vertical fragmentation, and international comovement at business cycle frequency. The third element might be relevant in the context of economic growth given the argument by Bhagwati (1988) and Melitz (2005) that export-oriented countries might benefit more from FDI 20 An extension of the model is left for future research to consider this type of entry.

\footnotetext{
${ }^{20}$ Contessi (2007) and Contessi (2010) study the international business cycle properties of an economy in which firms can both export and engage in multinational production. If firms are restricted to only export, as in Ghironi and Melitz (2005), the relationship between export sector size (or exporters entry) and home countries output dispersion (or output growth rates) is similar to the one studied here for multinational production and output. In that case, the interaction between the fixed cost of exporting and heterogeneous productivity induces sorting according to own productivity that determine similar results to the ones shown here, as the average productivity of the export sector increases with increases in the number of exporters, but at a decreasing rate. This feature depends crucially on the shape of the productivity distribution. In a model with both exports and multinational production, things are less straightforward. The results shown in this paper survive and the simple mechanism detailed here continues to be a valid way to reconcile the microeconomic and aggregate evidence. However, the relationship between the size of the exporting sector (or exporters entry) and output dispersion (or output growth rates) in the home economy, depends on the source of expansion of the export sector. If the export sector expands because the fixed cost of export decreases, the marginal contribution of export and new exporters to output and output growth is decreasing. If the size of the export sector increases because the fixed cost of multinational production increases and sales to the foreign economy switch to from multinational affiliates to exporters, then the average productivity of the export sector in the home economy increases.
} 


\section{References}

Alfaro, Laura, Areendam Chanda, Sebnem Kalemli-Ozcan, and Selin Sayek (2010): "Does Foreign Direct Investment Promote Growth? Exploring the Role of Financial Markets on Linkages," Journal of International Economics, 91(2), 2542-56.

Arnold, Jens Matthias, and Beata Smarzynska Javorcik (2009): "Gifted Kids or Pushy Parents? Foreign Direct Investment and Plant Productivity in Indonesia," Journal of International Economics, 1(79).

Bai, Yan, Jose-Victor Rios-Rull, and Kjetil Storesletten (2012): "Demand Shocks as Productivity Shocks," University of Minnesota manuscript.

Barba Navaretti, Giorgio, and Anthony Venables (2004): Multinational Firms in the World Economy. Princeton, NJ: Princeton University Press.

Bhagwati, Jagdish N. (1988): "Protectionism," in The Ohlin Lectures. Cambridge, MA: MIT Press.

Bloningen, Bruce A., and Miao Grace Wang (2005): "Inappropriate Pooling of Wealthy and Poor Countries in Empirical FDI Studies," in Does Foreign Direct Investment Promote Development?, ed. by E. M. G. Theodore H. Moran, and M. Blomström. Washington, DC: Institute for International Economics, 221-243.

Bloom, Nicholas, Raffaella Sadun, and John Van Reenen (2012): "Americans Do I.T. Better: US Multinationals and the Productivity Miracle," American Economic Review, 102(1), $167-201$.

Borensztein, Eduardo, Jose De Gregorio, and Jong-Wha Lee (1998): "How Does Foreign Direct Investment Affect Economic Growth?," Journal of International Economics, 45, $115-135$. 
Borga, Maria, and William J. Zeile (2004): "International Fragmentation of Production and the Intrafirm Trade of U.S. Multinational Companies," Bureau of Economic Analysis Working Paper No. 2004-02.

Bradford Jensen, J., and Lori Kletzer (2005): "Tradable Services: Understanding the Scope and Impact of Services Offshoring," in Brookings Trade Forum 2005, ed. by L. Brainard, and S. M. Collins. Washington, DC: Brooking Institution Press, 75-134.

Broda, Christian, and David Weinstein (2006): "Globalization and the Gains from Variety," Quarterly Journal of Economics, 121(2), 541-85.

Carkovic, Maria, and Ross Levine (2005): "Does Foreign Direct Investment Accelerate Economic Growth?," in The Impact of Foreign Direct Investment on Development: New Measurements, New Outcomes, New Policy Approaches, ed. by T. Moran. Washington, DC: Institute for International Economics, 195-220.

Cole, Matt, and Ron Davies (2011): "Optimal Tariffs, Tariff Jumping, and Heterogeneous Firms," European Economic Review, 55(4), 480-96.

Contessi, Silvio (2007): "Aggregate Implications of Firm-Level Heterogeneity in Open Economies," Doctoral Thesis, Johns Hopkins University, Baltimore, Maryland.

- (2010): "How Does Multinational Production Change International Comovement?," Federal Reserve Bank of St. Louis Working Paper No. 2010-041A.

Corrado, Carol, Paul Lengermann, and Larry Slifman (2009): "The Contribution of MNCs to U.S. Productivity Growth 1977-2000," in International Flows of Invisibles: Trade in Services and Intangibles in the Era of Globalization, ed. by M. Reinsdorf, and M. Slaughter. Chicago, IL: University of Chicago Press and NBER, 331-364.

Criscuolo, Chiara (2005): "Foreign Affiliates in OECD Economies: Presence, Performance, and Contribution to Host Countries," OECD Economic Studies, 41(2), 109-39. 
Criscuolo, Chiara, and Ralf Martin (2009): "Multinationals and U.S. Productivity Leadership: Evidence from Great Britain," Review of Economics and Statistics, 91(2), 263-281.

Eaton, Jonathan, Samuel Kortum, Brent Neiman, and John Romalis (2011): "Trade and the Global Recession," NBER Working Paper No. 16666.

Figlio, David, and Bruce Bloningen (2000): "The Effects of Direct Foreign Investment on Local Communities," Journal of Urban Economics, 48, 338-63.

Ghironi, Fabio, and Marc Melitz (2005): "International Trade and Macroeconomic Dynamics with Heterogeneous Firms," Quarterly Journal of Economics, 120, 865-915.

Görg, Holger, and David Greenaways (2004): "Much Ado about Nothing? Do Domestic Firms Really Benefit from Foreign Direct Investment?," World Bank Research Observer.

Greenwood, Jeremy, Zvi Hercowitz, and Gregory W. Huffman (1988): "Investment, Capacity Utilization, and the Real Business Cycle," American Economic Review, 78(3), 402-17.

Hanson, Gordon H., and Matthew J. Slaughter (2004): "The Role of Multinational Corporations in International Business Cycle Transmission," in Macroeconomic Policies in the World Economy: Proceedings of the Kiel Week Conference, ed. by R. Langhammer. Berlin: Springer Verlag, 133-155.

Harrison, Ann E., and Andres Rodriguez-Clare (2010): "Trade, Foreign Investment, and Industrial Policy," in Handbook of Development Economics, ed. by D. Rodrik, and M. R. Rosenzweig, vol. 5. Amsterdam: North-Holland, 4039-4214.

Helpman, Elhanan, Marc J. Melitz, and Stephen Yeaple (2004): "Export Versus FDI With Heterogeneous Firms," American Economic Review, 94(1), 300-16.

Hopenhayn, Hugo A. (1992): "Entry, Exit, and Firm Dynamics in Long Run Equilibrium," Econometrica, 60(5), 1127-50. 
Javorcik, Beata S., Wolfgang Keller, and James R. Tybout (2008): "Openness and Industrial Response in a Wal-Mart World: A Case Study of Mexican Soaps, Detergents and Surfactant Producers," World Economy, (12), 1558-1580.

Kose, M. Ayhan, Eswar Prasad, Kenneth Rogoff, and Shang-Jin Wei (2009): "Financial globalization: A reappraisal," IMF Staff Papers, 56(April), 8-62.

Lane, Philip, and Gian-Maria Milesi Ferretti (2007): "The External Wealth of Nations Mark II: Revised and Extended Estimates of Foreign Assets and Liabilities," Journal of International Economics, 73(November), 223-50.

Lubik, Thomas, and Kathryn N. Russ (2012): "Exchange Rate Volatility and Fluctuations of the Extensive Margin of Trade," Federal Reserve Bank of Richmond Economic Quarterly, $98(1), 51-76$.

McGrattan, Ellen (2012): "Transition to FDI Openness: Reconciling Theory and Evidence," Review of Economic Dynamics, 15(4), 437-58.

Melitz, Marc. J. (2003): "The Impact on Trade on Intra-industry Reallocations and Aggregate Industry Productivity," Econometrica, 71(6), 1695-725.

Melitz, Marc J. (2005): "Comment," in Does Foreign Direct Investment Promote Development?, ed. by E. M. G. Theodore H. Moran, and M. Blomström. Washington DC: Institute for International Economics, 273-277.

Naknoi, Kanda (2015): "Exchange Rate Volatility and Fluctuations of the Extensive Margin of Trade," Journal of Economic Dynamics and Control, 52, 322-339.

Petrin, Amil, and James Levinsohn (2012): "Measuring Aggregate Productivity Growth Using Plant-Level Data," RAND Journal of Economics, 43(4), 705-725.

Petrin, Amil, T. Kirk White, and Jerome P. Reiter (2011): "The Impact of Plant-Level Resource Reallocations and Technical Progress on U.S. Macroeconomic Growth," Review of Economic Dynamics, 14(1), 326. 
Ramondo, Natalia, and Veronica Rappoport (2010): "The Role of Multinational Production in a Risky Environment," Journal of International Economics, 81(2), 240-52.

Rivera-Batiz, Francisco L., and Luis A. Rivera-Batiz (1990): "The Effects of Direct Foreign Investment in the Presence of Increasing Returns Due to Specialization," Journal of Development Economics, 34(1), 287-307.

Rodrigue, Joel (2014): "Multinational Production, Exports and Aggregate Productivity," Review of Economic Dynamics, 17(2), 243-261.

Rodrik, Dani (2012): "Why We Learn Nothing from Regressing Economic Growth on Policies," Seoul Journal of Economics, 25(2), 137-151.

Russ, Kathryn N. (2007): "The Endogeneity of the Exchange Rate as a Determinant of FDI: A Model of Money, Entry, and Multinational Firms," Journal of International Economics, $71(2), 344-372$.

- (2009): "The New Theory of Foreign Direct Investment," International Finance, 12(1), 107-19.

Sauvant, Karl P., Padma Mallampally, and Persephone Economou (1993): "Foreign Direct Investment and International Migration," Transnational Corporations, 2(1).

Swenson, Deborah (2004): "Foreign Investment and the Mediation of Trade Flows," Review of International Economics, 12(4), 609-29.

UNCTAD (2011): World Investment Report 2011. Geneva: United Nations.

Wang, Pengfei, Yi Wen, and Zhiwei Xu (2012): "Two-Way Capital Flows and Global Imbalances: A Neoclassical Approach," Federal Reserve of St. Louis Working Paper No. 2012-016.

Yeaple, Stephen (2009): "Firm Heterogeneity and the Structure of U.S. Multinational Activity: An Empirical Analysis," Journal of International Economics, 78(2), 206-15. 
Zlate, Andrei (2008): "Offshore Production, Labor Migration and the Macroeconomy," Doctoral Thesis, Boston College, Massachussets.

(2010): "Offshore Production and Business Cycle Dynamics with Heterogeneous Firms," Board of Governors of the Federal Reserve System, International Finance Discussion Papers No. 995. 
Figure 1: FDI Stock-to-GDP Ratio and Real GDP Growth (1990-2000 and 2000-05)
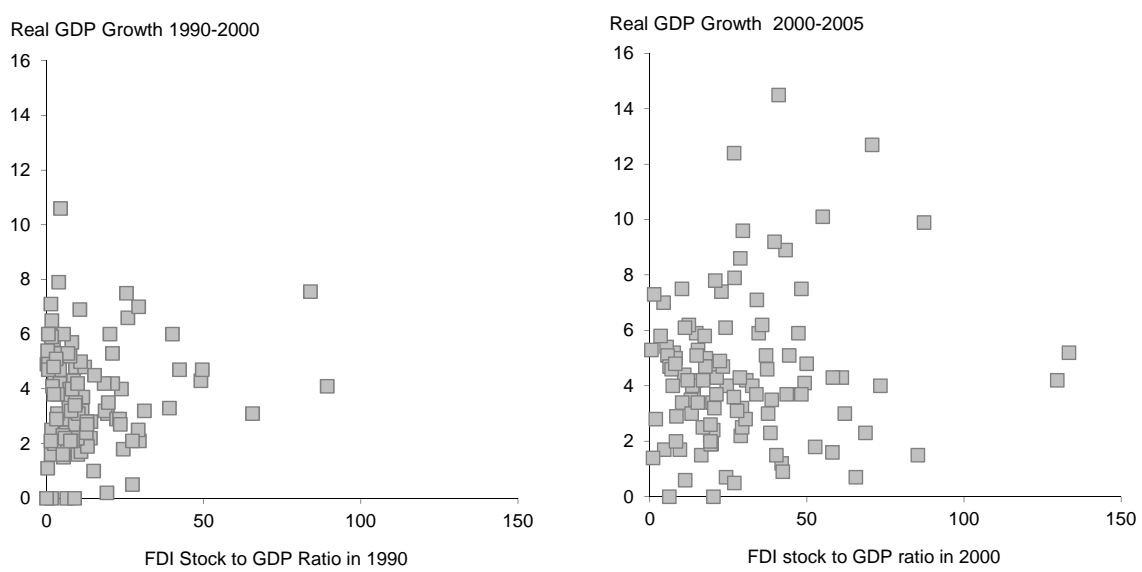

Source: 2007 World Development Indicators of the World Bank and (Lane and Milesi Ferretti, 2007). 
Figure 2: Measures of the Fixed Cost of Multinational Production: Ease of Establishment Index
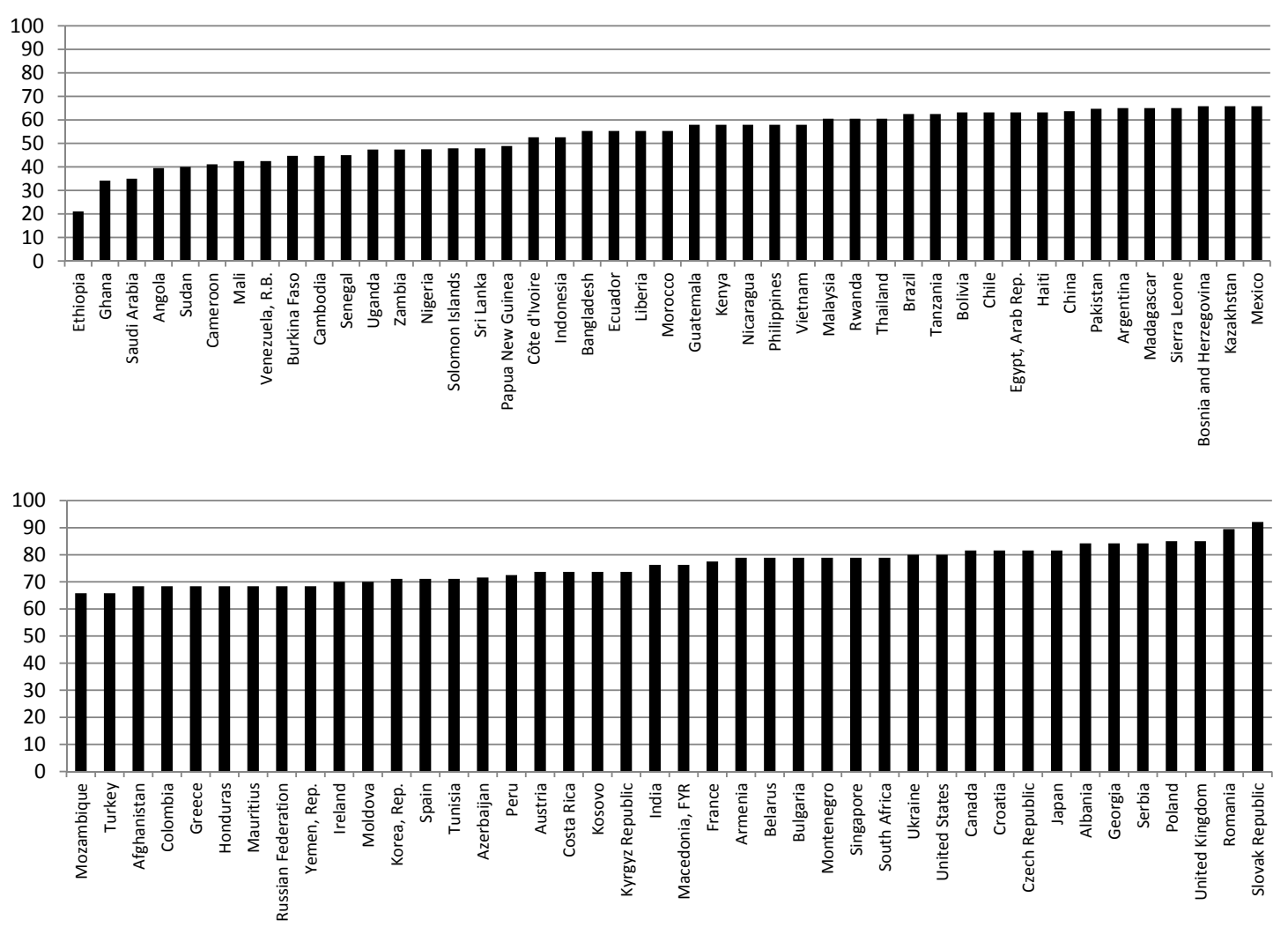

Note: The index is expressed in percentage points; the higher the score, the easier the establishment of affiliates. Source: Investing Across Borders Project of the World Bank. 
Figure 3: Measures of the Fixed Cost of Multinational Production: Number of Days and Number of Procedures to Establish an Affiliate

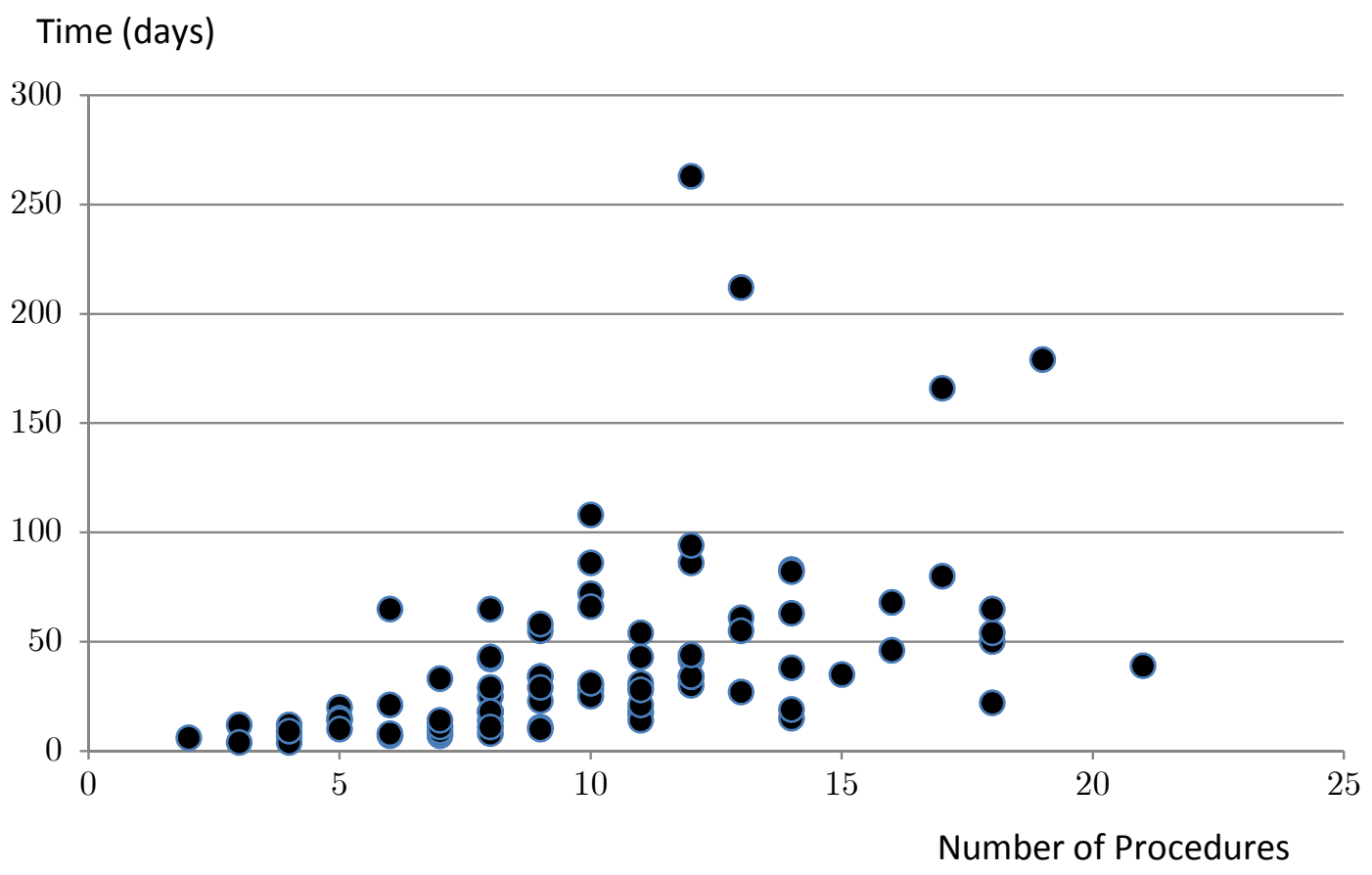


Figure 4: A Temporary Increase of Aggregate Productivity in the Home Economy
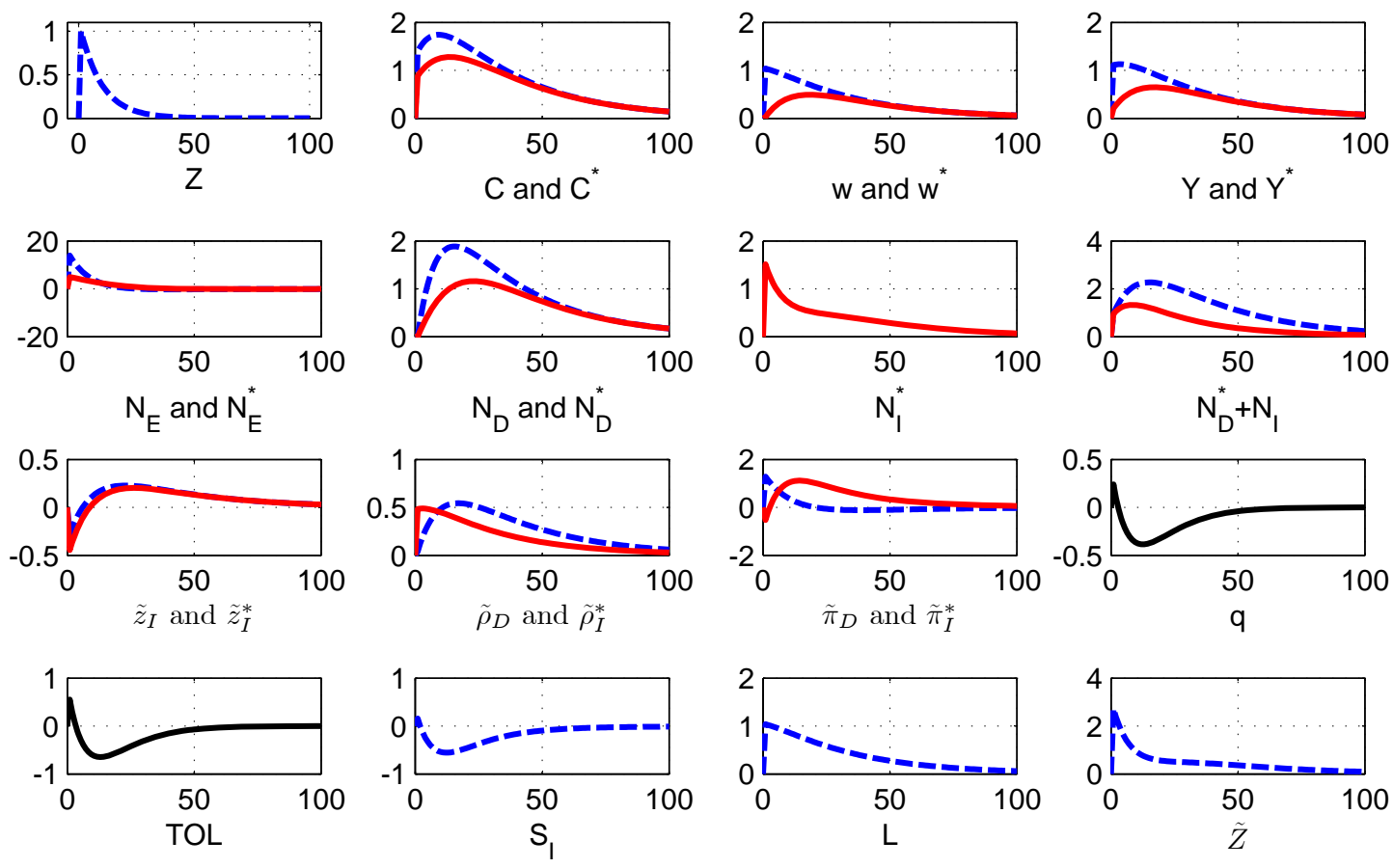

Note: Time periods are shown on the horizontal axes; percentage changes are shown on the vertical axes. The dashed lines represent variables for the home country; solid lines represent variables for the foreign country. See text for details. 
Figure 5: A Permanent Increase of Aggregate Productivity in the Home Country
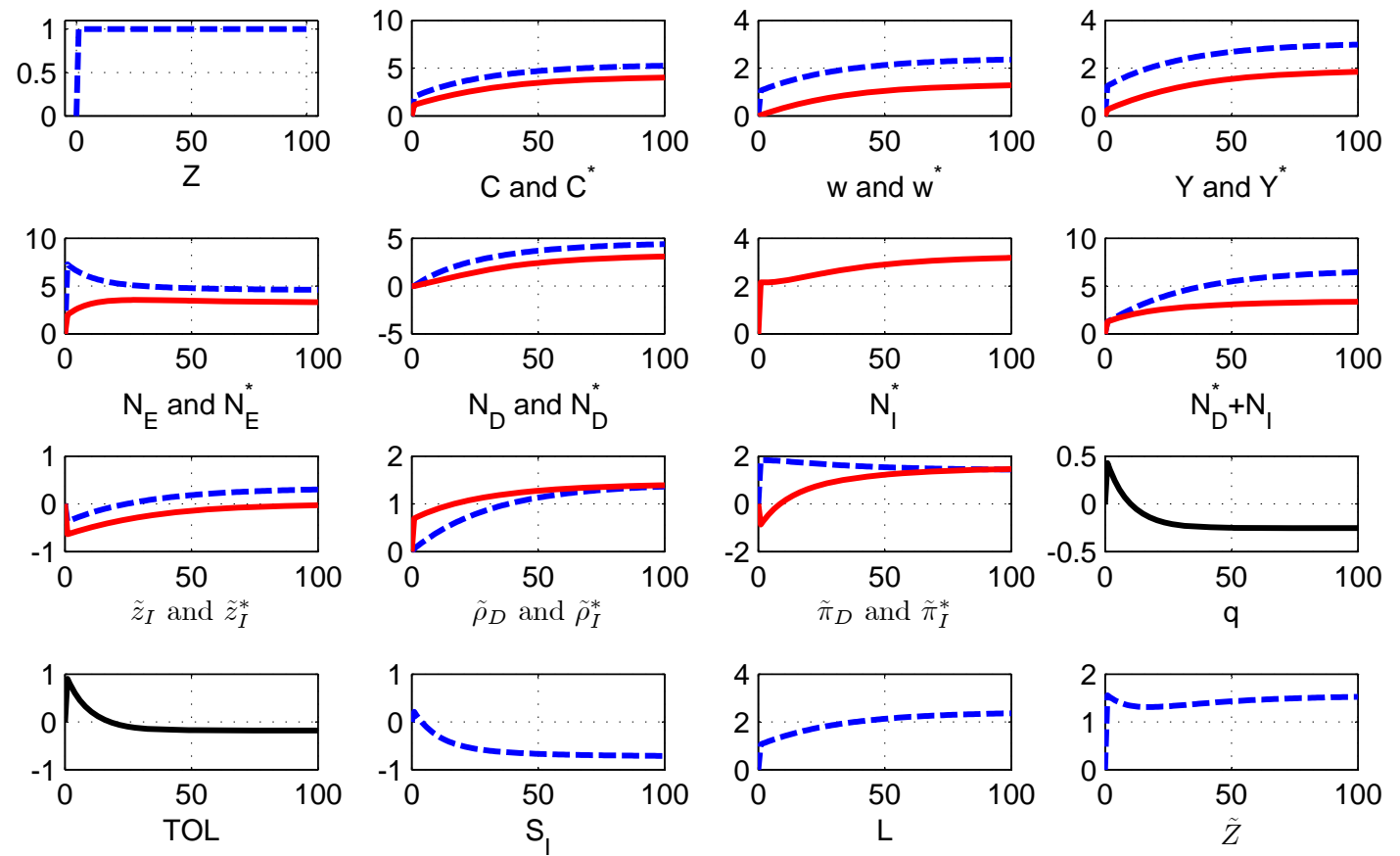

Note: Time periods are shown on the horizontal axes; percentage changes are shown on the vertical axes. The dashed lines represent variables for the home country; solid lines represent variables for the foreign country. See text for details. 
Figure 6: A Permanent Reduction of $f_{E}$ in the Home Country
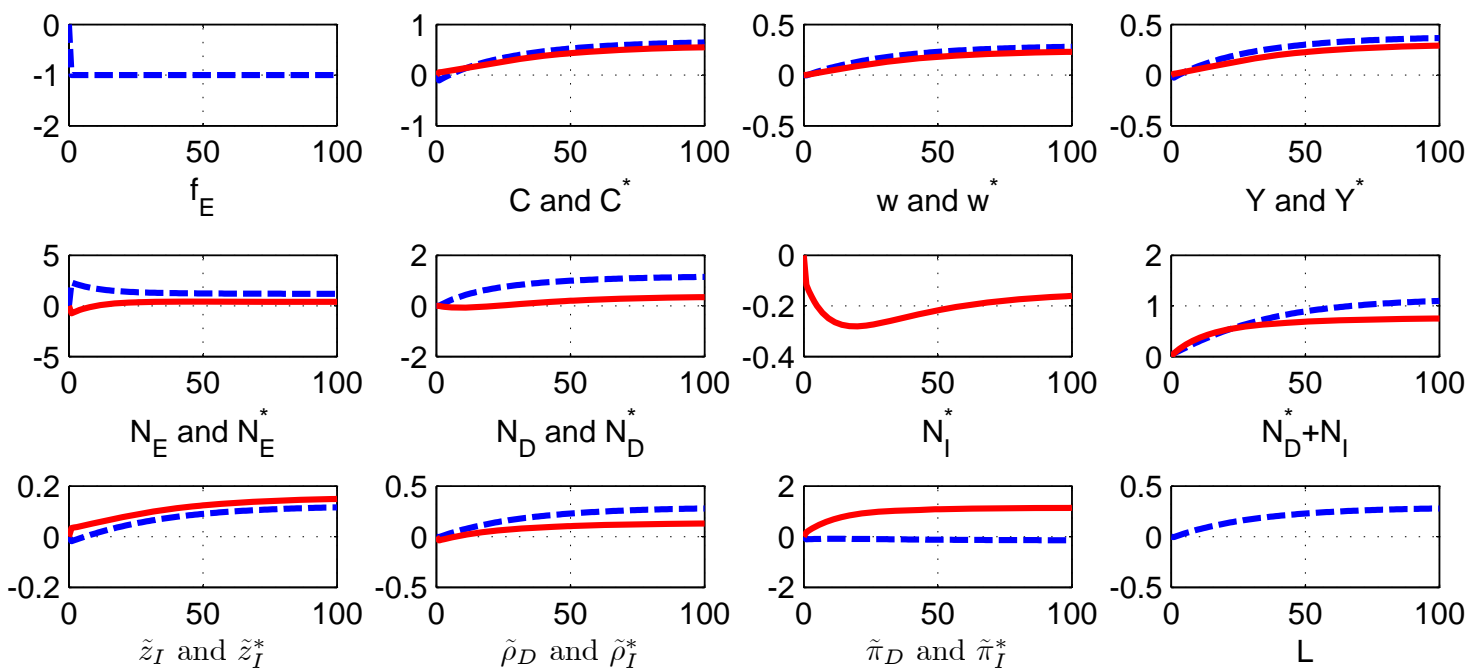

Note: Time periods are shown on the horizontal axes; percentage changes are shown on the vertical axes. The dashed lines represent variables for the home country; solid lines represent variables for the foreign country. See text for details. 
Figure 7: Selection into Multinational Production and Partitioning of the Productivity Distribution

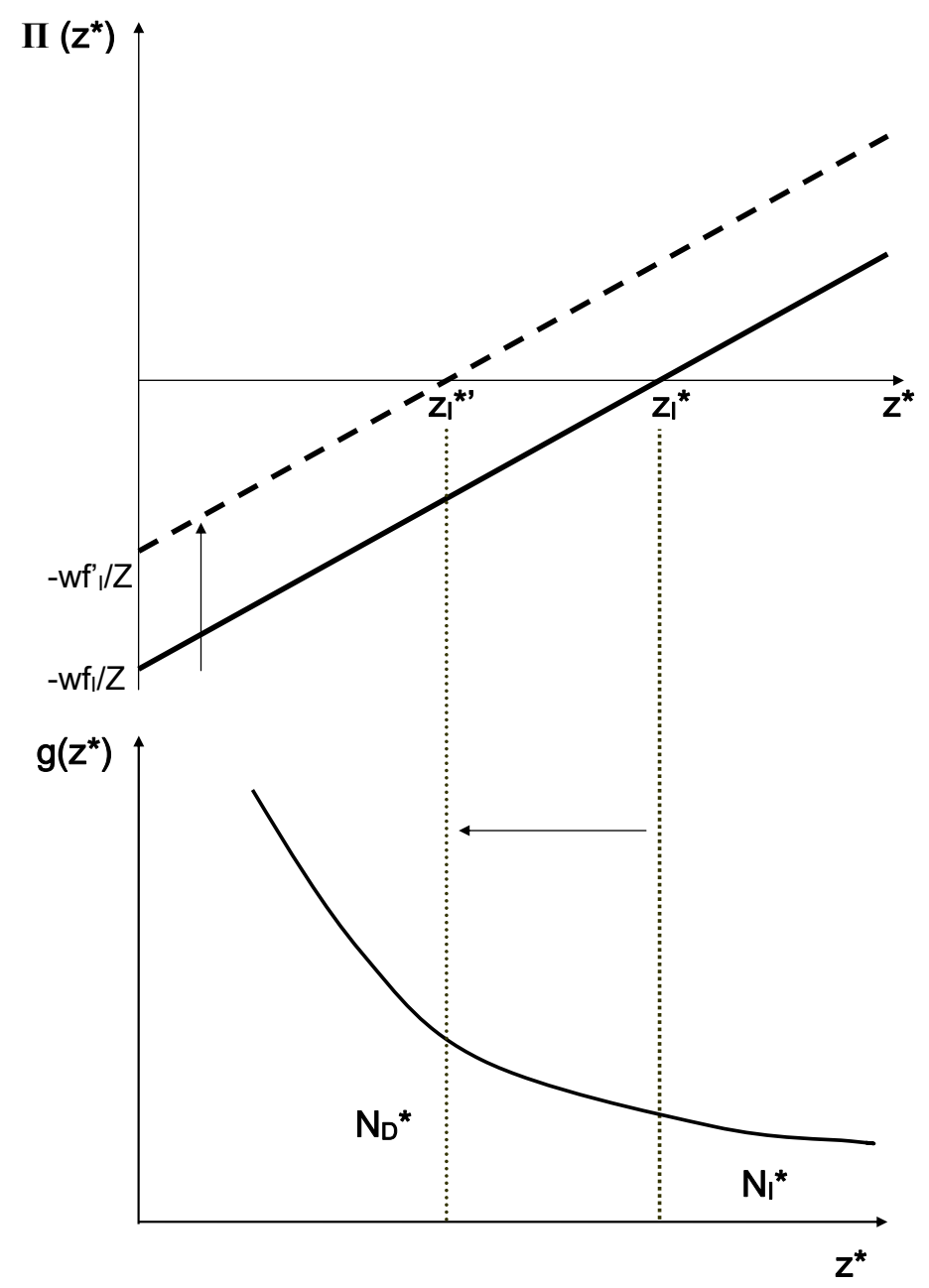


Figure 8: A Permanent Reduction of $f_{I}$ in the Home Country
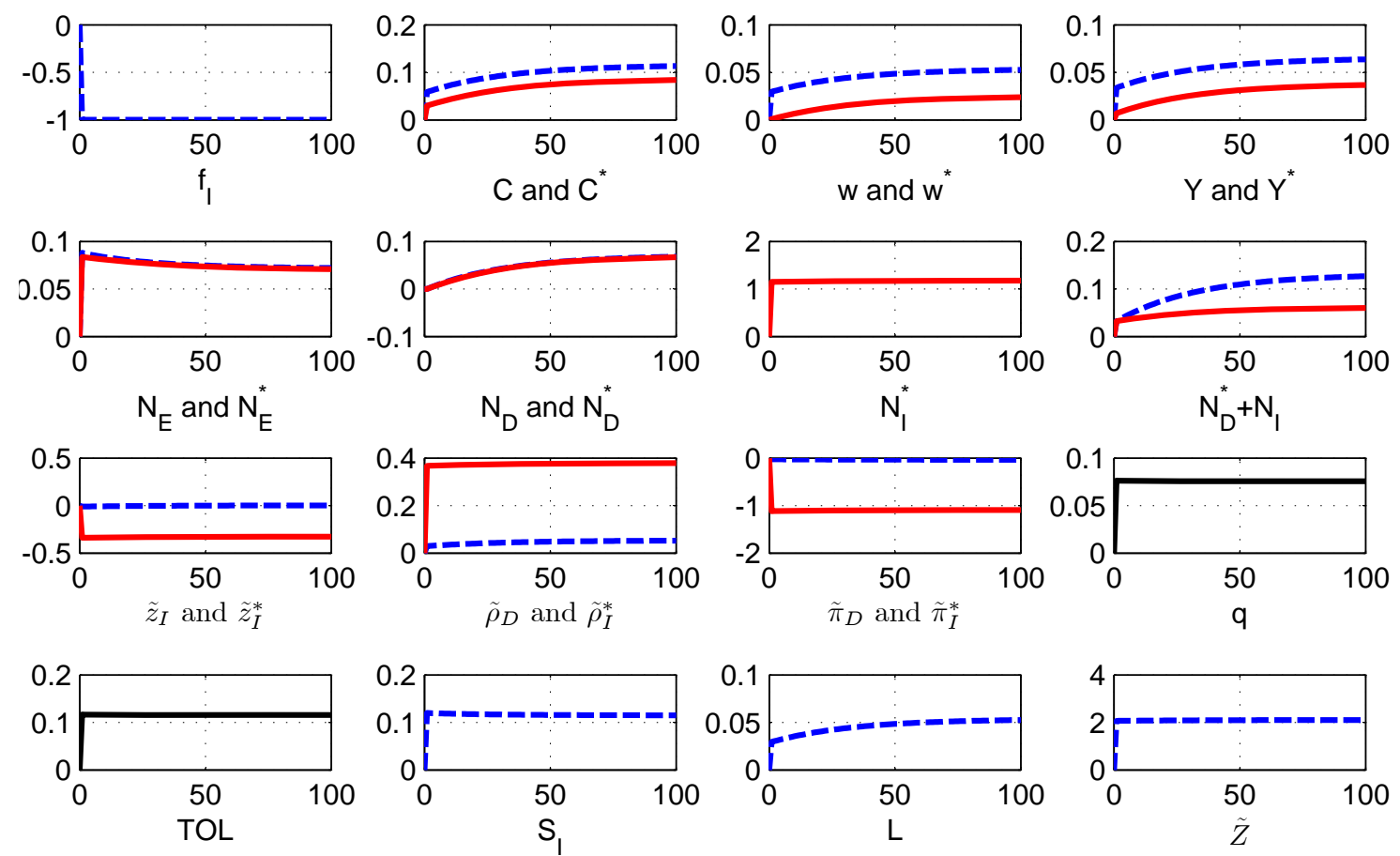

Note: Time periods are shown on the horizontal axes; percentage changes are shown on the vertical axes. Dashed lines represent variables for the home country, solid lines represent variables for the foreign country. 
Figure 9: Fixed Cost of Multinational Production and Selected Variables in the Steady State
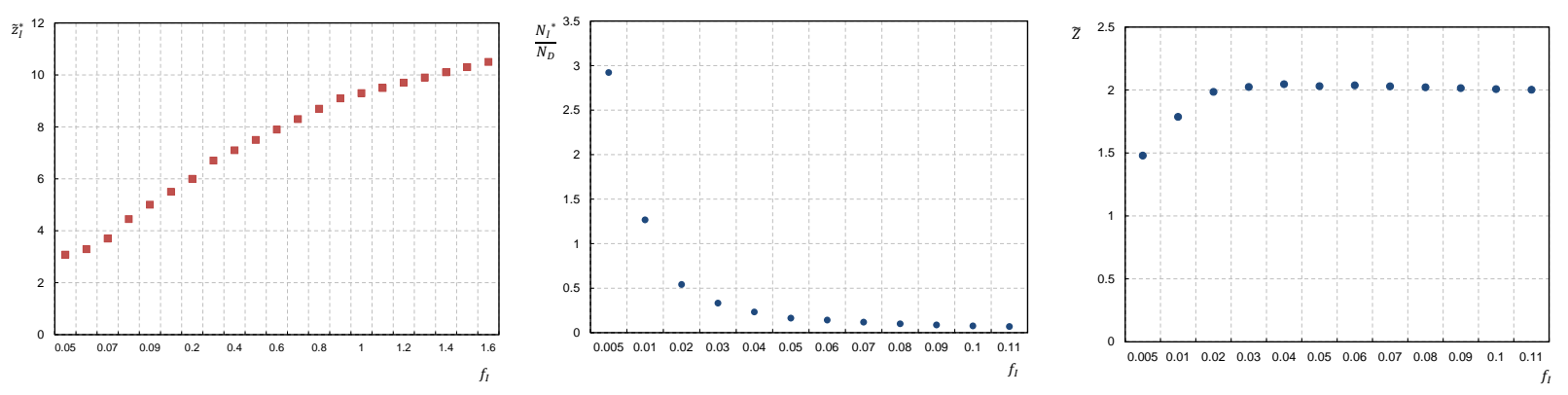

Figure 10: The Relationship Between Steady-State Share of Foreign Producers and Measured Output
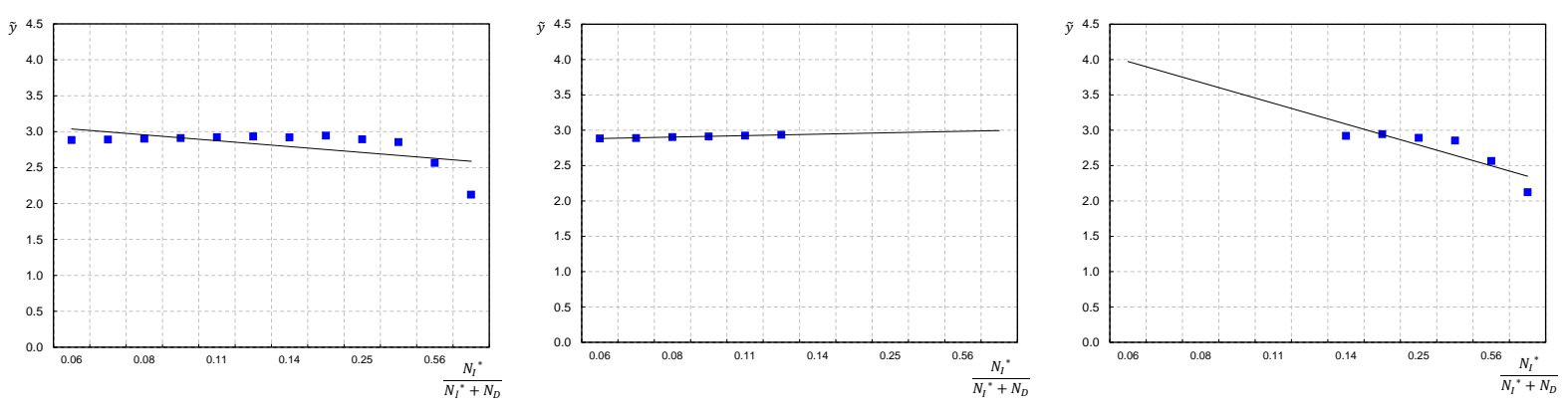
Figure 11: Dynamics of Average Productivity of Foreign Affiliates in the Home Country and Average Measured Productivity in the Home Country for Different Fixed Costs of Multinational Production
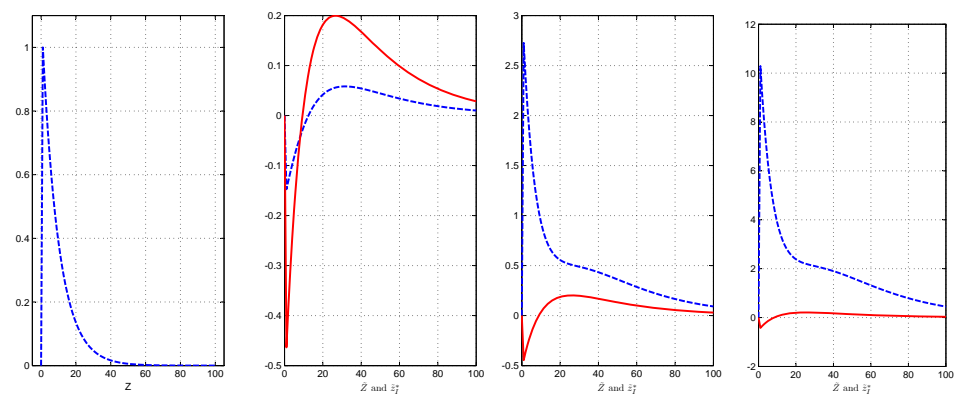

Note: Time periods are shown on the horizontal axes; percentage changes are shown on the vertical axes. Dashed lines represent variables for the home country, solid lines represent variables for the foreign country. The figure shows the response of a temporary aggregate productivity increase in the home country (left graph) on the average productivity of foreign affiliates in the home economy $\left(\tilde{z}_{t, I}^{*}\right)$ and on the measure of country-wide average productivity $\left(\tilde{Z}_{t}\right)$ in three cases in which the fixed cost of multinational production $f_{I}$ is $20 \%$ (second graph), 100\% (third graph), and 10 times the present discounted value of the fixed cost of entry $f_{E}$ (fourth graph). 
Table 1: Parameters for Calibration in the Benchmark Case

\begin{tabular}{ll}
\hline Parameter & Interpretation \\
\hline$\beta=0.96$ & Discount factor \\
$\sigma=3.8$ & Elasticity of substitution \\
$\chi=2$ & Elasticity of labor supply \\
$k=3.4$ & Shape parameter of the productivity distribution \\
$z_{\min }=1$ & Location parameter of the productivity distribution \\
$\delta=0.025$ & Probability of death shock \\
$\gamma=2$ & Parameter of relative risk aversion \\
$P D V\left(f_{E}\right)=\frac{1-\beta(1-\delta)}{\beta(1-\delta)} f_{E}=0.036$ & Entry fixed cost \\
$f_{I}=P D V\left(f_{E}\right)=0.036$ & Annualized FDI fixed cost \\
$\rho_{Z}=0.90$ & Persistence parameter of the productivity shock
\end{tabular}

Note: PDV denotes the present discounted value.

Table 2: Steady-State Values of Selected Endogenous Variables in the Benchmark Case

\begin{tabular}{ll}
\hline Steady-State Values & Interpretation \\
\hline$N_{E} / N_{D}=0.026$ & New entrants-to-producers ratio \\
$N_{I} /\left(N_{D}+N_{I}\right)=0.11$ & Affiliates-to-Home producers \\
$\widetilde{z}_{D}=1.7$ & Average productivity of home producers \\
$\widetilde{z}_{I}=2.8$ & Average productivity of home MNFs \\
$S_{D}=62 \%$ & Share of domestic sales in home expenditure \\
$S_{I}=38 \%$ & Share of affiliates' sales in home expenditure
\end{tabular}




\section{Online Appendix Not Meant For Publication}

\section{A Firms}

Consider a production process that involves only labor as the single factor of production. Producing a variety in the host economy requires a fixed cost and a variable cost equal to $\frac{f}{Z_{t}}$ and $\frac{1}{Z_{t} z} y_{t}$, respectively.

Therefore, this technology has a cost function with the following structure:

$$
\Gamma_{t}(\omega)=W_{t} l_{t}(z, \omega)=W_{t}\left(\frac{1}{Z_{t}} f_{t}+\frac{1}{Z_{t} z} y_{t}(\omega)\right)=\underbrace{\frac{W_{t} f_{t}}{Z_{t}}}_{\text {fixed cost }}+\underbrace{\frac{W_{t}}{Z_{t} z} y_{t}(\omega)}_{\text {variable cost }},
$$

where $W_{t}$ is the wage rate, $l_{t}(z)$ represents labor use, and $y_{t}(\omega)$ is the level of firm output. The fixed cost can be interpreted as the annualization of a once-and-for-all sunk cost or a recurrent fixed cost that is independent of the output level. Such cost function implies that average costs $\frac{\Gamma_{t}(\omega)}{y_{t}(\omega)}=\frac{W_{t} f_{t}}{Z_{t} y_{t}}+\frac{1}{Z_{t} z}$ decrease with the level of output. Variable production costs and marginal costs are $\left(\frac{W_{t}}{Z_{t} z}\right) y_{t}(\omega)$ and $\frac{W_{t}}{Z_{t} z}$, respectively.

Domestic PRoduction. Domestic producers, who do not incur a fixed cost of production, determine prices $p_{t}(z ; \omega)$ by maximizing the following profit function for the differentiated good $\omega$, considering the demand-based revenues $r_{t}(z ; \omega)$

$$
\begin{gathered}
\Pi_{D, t}(z ; \omega)=p_{t}(z ; \omega) y_{t}(z ; \omega)-W_{t} l_{D, t}(z)=p_{t}(z ; \omega) y_{t}(\omega)-\frac{W_{t}}{Z_{t} z} y_{t}(\omega) \\
r_{t}(z ; \omega)=p_{t}(z ; \omega) y_{t}(z ; \omega)=y_{t}(z ; \omega)^{1-\frac{1}{\sigma}} C_{t}^{\frac{1}{\sigma}} P_{t} .
\end{gathered}
$$

Accordingly, the marginal cost is $\frac{\partial \Gamma_{t}(\omega)}{\partial y_{t}(\omega)}=\frac{W_{t}}{Z_{t} z}$ and marginal revenue is defined as

$$
\frac{\partial\left[p_{t}(z ; \omega) y_{t}(\omega)\right]}{\partial y_{t}(\omega)}=\left(1-\frac{1}{\sigma}\right) y_{t}(z ; \omega)^{-\frac{1}{\sigma}} \underbrace{y_{t}(z ; \omega)^{\frac{1}{\sigma}} P_{t}}_{p_{t}(z ; \omega)}=\left(1-\frac{1}{\sigma}\right) p_{t}(z ; \omega) .
$$


By first-order condition,

$$
\left(1-\frac{1}{\sigma}\right) p_{D, t}(z ; \omega)=\frac{W_{t}}{Z_{t} z} \Longleftrightarrow p_{D, t}(z ; \omega)=\frac{W_{t}}{Z_{t} z} \mu .
$$

Given the real wage $w_{t}=W_{t} / P_{t}$, the relative price is

$$
\rho_{D, t}(z ; \omega) \equiv \frac{p_{D, t}(z ; \omega)}{P_{t}}=\frac{w_{t}}{Z_{t} z} \mu
$$

which can be substituted into the profit function to obtain optimal profit, in nominal and real terms, as follows:

$$
\pi_{D, t}(z ; \omega)=\frac{\Pi_{D, t}(z ; \omega)}{P_{t}}=\frac{1}{\sigma} \rho_{D, t}^{1-\sigma}(z ; \omega) C_{t}
$$

Multinational PROduction. Producers that engage in multinational production must bear a fixed cost of investing abroad equal to $W_{t}^{*} f_{I, t}^{*} / Z_{t}^{*}$ and solve the following maximization problem:

$$
\max \Pi_{I, t}(z ; \omega)=e_{t}\left[p_{t}(z ; \omega) y_{t}^{*}(z ; \omega)-W_{t}^{*} l(z)-\frac{W_{t}^{*} f_{I, t}^{*}}{Z_{t}^{*}}\right] .
$$

Thus,

$$
\rho_{I, t}(z ; \omega) \equiv \frac{p_{I, t}(z ; \omega)}{P_{t}^{*}}=\frac{w_{t}^{*}}{Z_{t}^{*} z} \mu
$$

The optimal profit from the affiliates' production, relative to the price index in the market of location of the mother firm, is

$$
\pi_{I, t}(z ; \omega)=\frac{Q_{t}}{\sigma} \rho_{I, t}^{1-\sigma}(z ; \omega) C_{t}^{*}-Q_{t} \frac{w_{t}^{*} f_{I, t}^{*}}{Z_{t}^{*}}
$$

\section{A.1 Cutoff points: Marginal Affiliates}

The cutoff point $z_{I, t}$ is determined as a zero net profit condition for the firm that makes exactly enough operating profit to cover the fixed cost of entry in the foreign country. For the multinational part of a firm's business, the zero profit condition is $\pi_{I, t}-\frac{w_{t}^{*} f_{I, t}^{*}}{Z_{t}}=0$. 
Therefore,

$$
\begin{gathered}
z_{I, t}: \pi_{I, t}(z ; \omega)=0 \Longleftrightarrow \frac{Q_{t}}{\sigma}\left[\rho_{I, t}(z ; \omega)\right]^{1-\sigma} C_{t}^{*}=Q_{t} \frac{w_{t}^{*} f_{I, t}^{*}}{Z_{t}^{*}} \\
\frac{Q_{t}}{\sigma}\left[\frac{1}{z_{I} Z_{t}^{*}} \frac{\sigma}{\sigma-1} w_{t}^{*}\right]^{1-\sigma} C_{t}^{*}=\frac{Q_{t} w_{t}^{*} f_{I, t}^{*}}{Z_{t}^{*}} \\
z_{I, t}=\left(\frac{f_{I, t}^{*}}{C_{t}^{*}}\right)^{\frac{1}{\sigma-1}}\left(\frac{w_{t}^{*} \sigma}{Z_{t}^{*}}\right)^{\frac{\sigma}{\sigma-1}}\left(\frac{1}{\sigma-1}\right) .
\end{gathered}
$$

Now, the cutoff point for multinational production can be used to determine average profits of the affiliates $\tilde{\pi}_{I, t}$ :

$$
\tilde{\pi}_{I, t}=Q_{t}(\nabla-1) \frac{w_{t}^{*} f_{I, t}^{*}}{Z_{t}^{*}} .
$$

\begin{tabular}{|c|c|c|c|}
\hline & Entry & Domestic Production & Multinational Production \\
\hline Variable labor cost & & $w_{t} l_{D, t}(z)$ & $w_{t} l_{I, t}(z)$ \\
\hline Annualized fixed cost & & & $\frac{w_{t} f_{I, t}}{Z_{t}}$ \\
\hline Once-and-for-all cost & $\frac{w_{t} f_{E, t}}{Z_{t}}$ & & \\
\hline
\end{tabular}

\section{B Labor Market Clearing}

The labor supplied in the economy meets demand, which depends on the variable costs to produce and the fixed production costs to capture entry into different segments or markets.

LABOR USED FOR PRODUCTION. A generic firm $i$ produces $z Z_{t}$ units of variety $\omega$ per worker. Considering separately work that is used for domestic and affiliates' production, $l_{D, t}(z)$ and $l_{I, t}(z)$ are the number of workers hired by domestic and foreign firms in the home economy. LABOR USED AS INVESTMENT. New entrants hire $f_{E, t}$ workers as an entry cost. Each foreign firm producing domestically hires $f_{I, t}$ domestic workers per period to carry out production in its affiliates. Profits from domestic sales for a domestic firm with idiosyncratic productivity 
$z$ are

$$
\begin{aligned}
\pi_{D, t}(z) & =\underbrace{\rho_{D, t}(z)}_{\frac{\sigma}{\sigma-1} \frac{w_{t}}{z Z_{t}} z Z_{t} l_{D, t}(z)} \underbrace{y_{D, t}}_{D, t}-w_{t} l_{D, t}(z)= \\
& =\frac{1}{\sigma-1} w_{t} l_{D, t}(z) .
\end{aligned}
$$

The profits from multinational sales at home made by a foreign firm with productivity $z$ located in the home country are

$$
\begin{aligned}
\Pi_{I, t}^{*}(z) & =\frac{1}{e_{t}}[\underbrace{p_{I, t}\left(z^{*}\right)}_{\frac{\sigma}{\sigma-1} \frac{W_{t}}{z^{*} Z_{t}}} \underbrace{y_{I, t}}_{Z_{t} l_{I, t}(z)}-W_{t}]= \\
\pi_{I, t}^{*}(z) & =\frac{\Pi_{I, t}^{*}(z)}{P^{*}}=\frac{1}{e_{t} P_{t}^{*}} \frac{P_{t}}{P_{t}}\left[\frac{\sigma}{\sigma-1} W_{t} l_{I, t}\left(z^{*}\right)-W_{t}\left(l_{I, t}\left(z^{*}\right)+\frac{f_{I}}{Z_{t}}\right)\right] \\
& =\frac{1}{Q_{t}}\left(\frac{1}{\sigma-1} w_{t} l_{I, t}\left(z^{*}\right)-w_{t} \frac{f_{I}}{Z_{t}}\right) .
\end{aligned}
$$

Notice that foreign firms hire labor in the domestic country and pay the domestic wage rate, but the foreign firms transfer their idiosyncratic technology $\left(z^{*}\right)$ to the home country. From the optimal profits above, I can derive the average amount of labor hired to cover domestic sales and affiliates' sales of the foreign average firm as follows:

$$
\begin{gathered}
\tilde{l}_{D, t}(z)=(\sigma-1) \frac{\tilde{\pi}_{D, t}}{w_{t}} \\
\widetilde{l}_{I, t}\left(z^{*}\right)=(\sigma-1) \frac{Q_{t} \pi_{I, t}^{*}}{w_{t}}+(\sigma-1) \frac{f_{I, t}}{Z_{t}}
\end{gathered}
$$

This implies that the total amount of production labor hired in the home economy in every period is

$$
(\sigma-1) N_{D, t}\left[\frac{\tilde{\pi}_{D, t}}{w_{t}}\right]+(\sigma-1) N_{I, t}^{*}\left[\frac{Q_{t} \widetilde{\pi}_{I, t}^{*}}{w_{t}}+\frac{f_{I, t}}{Z_{t}}\right]
$$


To obtain total labor demand in the economy, I must consider the "investment" labor hired by new entrants $N_{E, t} f_{E, t} / Z_{t}$ and by affiliates $N_{I, t}^{*} f_{I, t} / Z_{t}$

$$
L_{t}^{D}=(\sigma-1)\left[\frac{\widetilde{\pi}_{D, t}}{w_{t}}\right] N_{D, t}+(\sigma-1)\left[\frac{Q_{t} \widetilde{\pi}_{I, t}^{*}}{w_{t}}+\frac{f_{I, t}}{Z_{t}}\right] N_{I, t}^{*}+\frac{f_{E, t}}{Z_{t}} N_{E, t}+\frac{f_{I, t}}{Z_{t}} N_{I, t}^{*} .
$$

Since the labor supply is $L_{t}^{S}=w_{t}^{\frac{1}{x-1}}$, equilibrium is such that

$$
\begin{aligned}
w_{t}^{\frac{1}{x-1}} & =(\sigma-1) \frac{\widetilde{\pi}_{D, t}}{Q_{t} \widetilde{\pi}_{I, t}^{*}} \frac{f_{I, t}}{Z_{t}} N_{D, t}+\frac{f_{E, t}}{Z_{t}} N_{E, t}+[(\sigma-1) \nabla+1] N_{I, t}^{*} \frac{f_{I, t}}{Z_{t}} \\
w_{t} & =\left[(\sigma-1) \frac{\widetilde{\pi}_{D, t}}{Q_{t} \widetilde{\pi}_{I, t}^{*}} \frac{f_{I, t}}{Z_{t}} N_{D, t}+\frac{f_{E, t}}{Z_{t}} N_{E, t}+[(\sigma-1) \nabla+1] N_{I, t}^{*} \frac{f_{I, t}}{Z_{t}}\right]^{\chi-1} .
\end{aligned}
$$

Analogously for the foreign country,

$$
w_{t}^{*}=\left[(\sigma-1) \frac{\widetilde{\pi}_{D, t}^{*}}{Q_{t} \widetilde{\pi}_{I, t}} \frac{f_{I, t}^{*}}{Z_{t}^{*}} N_{D, t}^{*}+\frac{f_{E, t}^{*}}{Z_{t}^{*}} N_{E, t}^{*}+[(\sigma-1) \nabla+1] N_{I, t} \frac{f_{I, t}^{*}}{Z_{t}^{*}}\right]^{\chi-1} .
$$

\section{B.1 Real Exchange Rate}

Aggregating the average price for domestic- and affiliate-produced varieties $\widetilde{p}_{D, t} \equiv p_{D, t}\left(\widetilde{z}_{D}\right)$ and $\widetilde{p}_{I, t} \equiv p_{I, t}\left(\widetilde{z}_{I}\right)$ and using the number of domestic- and foreign-owned firms as weights, the aggregate welfare-based price indices are

$$
\begin{gathered}
P_{t}=\left[N_{D, t} p_{D, t}\left(\widetilde{z}_{D}\right)^{1-\sigma}+N_{I, t}^{*} p_{I, t}^{*}\left(\widetilde{z}_{I}\right)^{1-\sigma}\right]^{\frac{1}{\sigma-1}} \\
P_{t}^{*}=\left[N_{D, t}^{*} p_{D, t}\left(\widetilde{z}_{D}^{*}\right)^{1-\sigma}+N_{I, t} p_{I, t}\left(\widetilde{z}_{I}\right)\right]^{\frac{1}{\sigma-1}}
\end{gathered}
$$

Thus, in each country the domestic price index depends on the number of varieties and the average price of domestic goods sold domestically by domestic producers and goods produced domestically by foreign firms through affiliates, both sold in the domestic market. Dividing 
by the price indices $P_{t}$ and $P_{t}^{*}$, and defining $S_{D} \equiv \widetilde{\rho}_{D}^{1-\sigma} N_{D}$ and $S_{I} \equiv \widetilde{\rho}_{I}^{1-\sigma} N_{I}$ as the steadystate spending for the domestic good and for the goods produced domestically by MNFs, I rewrite the equivalent price indices as expenditure shares $1=S_{D}+S_{I}^{*}$ and $1=S_{D}^{*}+S_{I}$. If I use the relevant welfare-based price indices, a welfare-based real exchange rate $Q_{t} \equiv e_{t} P_{t}^{*} / P_{t}$ can be constructed as follows:

$$
Q_{t}^{1-\sigma}=\frac{N_{D, t}^{*}\left(T O L_{t} \frac{\widetilde{z}_{D, t}}{\tilde{z}_{D, t}^{*}}\right)^{1-\sigma}+N_{I, t}\left(T O L_{t} \frac{\widetilde{z}_{D, t}}{\widetilde{z}_{I, t}}\right)^{1-\sigma}}{N_{D, t}+N_{I, t}^{*}\left(\frac{\widetilde{z}_{D, t}}{\widetilde{z}_{I, t}^{*}}\right)^{1-\sigma}},
$$

where $T O L_{t} \equiv\left(e_{t} \frac{W_{t}^{*}}{Z_{t}^{*}}\right) /\left(\frac{W_{t}}{Z_{t}}\right)$ are the terms of labor ${ }^{21}$

A transformation of $Q_{t}$ aimed at resembling the construction of CPI-based real exchange rates can be obtained following Ghironi and Melitz (2005) and Broda and Weinstein (2006), and redefining price indices as follows: $P=N_{H}^{\frac{1}{1-\sigma}} \widetilde{P}$, and $P^{*}=N_{H}^{*} \frac{1}{1-\sigma} \widetilde{P}^{*}$, where the aggregate price index $\widetilde{P}$ is a weighted average of $\widetilde{p}_{D, t}$ and $\widetilde{p}_{I, t}^{*}$, and $\widetilde{P}^{*}$ of $\widetilde{p}_{D, t}$ and $\widetilde{p}_{I, t}^{*}$. This allows for the redefinition of $q_{t}=e_{t} \widetilde{P}^{*} / \widetilde{P}$ so that $Q_{t}=\left(N_{H, t} / N_{H, t}^{*}\right)^{\frac{1}{\sigma-1}} q_{t}$.

$Q_{t}$ and $q_{t}$ differ in this sense: $q_{t}<1$ implies that average prices are higher in the home country, whereas $Q_{t}$ measures the difference in consumers' welfare derived from spending a given nominal amount in each market - hence, if $Q_{t}>1$ and $q_{t}<1$. This implies that consumers derive higher utility from spending the same amount in the home market with higher prices. This is the case if the number of varieties in the home country is sufficiently above the number of varieties in the foreign country that it compensates for the price differential. Therefore, $q_{t}$ is the $R E R$ constructed using the CPI index and log-linearized as follows:

$$
q_{t}=\left(\frac{N_{D, t}^{*}+N_{I, t}}{N_{D, t}+N_{I, t}^{*}}\right)^{\frac{1}{\sigma-1}} Q_{t}
$$

\footnotetext{
${ }^{21}$ If home effective labor $\left(\frac{W_{t}}{Z_{t}}\right)$ appreciates, then the $T O L_{t}$ decreases, and the home economy as a whole becomes a less attractive location. The TOL should be considered such that if $T O L_{t}>1$, a firm with a given level of idiosyncratic productivity $z$ can produce at a lower cost in the home country than in the foreign country.
} 


$$
\begin{aligned}
\widehat{q}_{t}=\widehat{T O L}_{t}+S_{I}\left[\widehat{\widetilde{z}}_{I, t}^{*}-\widehat{\widetilde{z}}_{I, t}\right] \quad & \frac{1}{\sigma-1}\left\{\left(S_{D}-\frac{N_{D}}{N_{D}+N_{I}}\right)\left[\left(\widehat{N}_{D, t}^{*}-\widehat{N}_{D, t}\right)\right]+\right. \\
& \left.+\left(S_{I}-\frac{N_{I}}{N_{D}+N_{I}}\right)\left(\widehat{N}_{I, t}-\widehat{N}_{I, t}^{*}\right)\right\}
\end{aligned}
$$

where variables with a hat represent percentage deviations from the steady state, where $S_{D}$ and $S_{I}$ are the steady-state share of spending in the goods produced domestically by home producers and foreign affiliates.

\section{Steady State}

I drop the $t$ subscript to identify steady-state levels of the variables and assume a symmetric steady-state such that $f_{E}=f_{E}^{*}, \tau=\tau^{*}, f_{I}=f_{I}^{*}, L=L^{*}, Z=Z^{*}=1, C=C^{*}, \widetilde{z}_{I}=\widetilde{z}_{I}^{*}$, $\widetilde{\rho}_{I}=\widetilde{\rho}_{I}^{*}, N_{D}=N_{D}^{*}, N_{E}=N_{E}^{*}, N_{I}=N_{I}^{*}, \widetilde{\pi}_{D}=\widetilde{\pi}_{D}^{*}, N_{I}=N_{I}^{*}, \widetilde{v}=\widetilde{v}^{*}, w=w^{*}$, and $r=r^{*}$. Morover, $Q=1$.

I first solve for $\widetilde{z}_{I}$, using steady-state average profits for different market segments.

- Using the Euler equation for share holdings, and considering that in steady-state $C_{t}=$ $C_{t+s}=C$,

$$
\begin{aligned}
& \widetilde{v}=\beta(1-\delta)\left[\left(\frac{C}{C}\right)^{-\gamma}(\widetilde{v}+\widetilde{\pi})\right] \\
& \widetilde{v}=\frac{1}{\Xi} \widetilde{\pi} ; \Xi \equiv \frac{1-\beta(1-\delta)}{\beta(1-\delta)} .
\end{aligned}
$$

Thus, the system

$$
\left\{\begin{array}{cc}
\widetilde{v}=f_{E} w & \text { free entry condition } \\
\widetilde{v}=\frac{1}{\Xi} \widetilde{\pi} & \text { Euler equation for share holdings }
\end{array}\right.
$$

implies

$$
\Xi f_{E} w=\widetilde{\pi}_{D}+\frac{N_{I}}{N_{D}} \widetilde{\pi}_{I}
$$


- Using the optimal pricing rules, the steady-state ratios of average prices can be defined as

$$
\begin{gathered}
\frac{\widetilde{\rho}_{D}}{\widetilde{\rho}_{I}}=\left[\frac{w}{\widetilde{z}_{D}} \mu\right]\left[\frac{w^{*}}{\widetilde{z}_{I}} \mu\right]^{-1}=\frac{\widetilde{z}_{I} w}{\widetilde{z}_{D} w^{*}} \\
\frac{\widetilde{\rho}_{D}}{\widetilde{\rho}_{I}^{*}}=\left[\frac{w}{\widetilde{z}_{D}} \mu\right]\left[\frac{w}{\widetilde{z}_{I}^{*}} \mu\right]^{-1}=\frac{\widetilde{z}_{I}^{*}}{\widetilde{z}_{D}} .
\end{gathered}
$$

The steady-state affiliates' zero profit condition is

$$
\tilde{\pi}_{I}=(\nabla-1) w^{*} f_{I}^{*}
$$

Rearranging

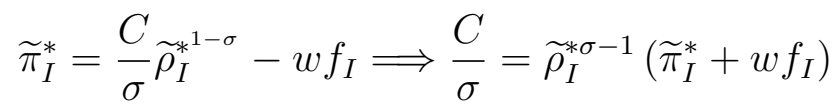

yields

$$
\begin{aligned}
\widetilde{\pi}_{D} & =\left[\frac{C}{\sigma}\right] \widetilde{\rho}_{D}^{1-\sigma}=\left[\widetilde{\rho}_{I}^{* \sigma-1}\left(\widetilde{\pi}_{I}^{*}+w f_{I}\right)\right] \widetilde{\rho}_{D}^{1-\sigma}=\left(\frac{\widetilde{\rho}_{D}}{\widetilde{\rho}_{I}^{*}}\right)^{1-\sigma}\left(\widetilde{\pi}_{I}^{*}+w f_{I}\right) \\
& =\left(\frac{\widetilde{z}_{I}^{*}}{\widetilde{z}_{D}}\right)^{1-\sigma}\left(\widetilde{\pi}_{I}^{*}+w f_{I}\right) .
\end{aligned}
$$

- The law of motion for the total number of firms implies that in the steady-state

$$
N_{E}=\frac{\delta}{1-\delta} N_{D}
$$

which can be combined with the steady-state aggregate accounting equation

$$
C=w L+\underbrace{N_{D} \tilde{\pi}_{D}+N_{I} \tilde{\pi}_{I}}_{N_{D} \tilde{\pi}}-w N_{E} f_{E}
$$

to obtain equation $C .12$ and the corresponding equation for the foreign country:

$$
\frac{C}{w}=L+\underbrace{\frac{1-\delta}{\delta} N_{E}}_{N_{D}} \underbrace{\frac{1-\beta(1-\delta)}{\beta(1-\delta)} w f_{E}}_{\widetilde{\pi}}-N_{E} f_{E}
$$




$$
\begin{gathered}
\frac{C}{w}=L+\left[\frac{1-\beta(1-\delta)}{\delta \beta}-1\right] N_{E} f_{E}= \\
=L+\left[\frac{1-\beta+\delta \beta-\delta \beta}{\delta \beta}\right] \frac{\delta}{1-\delta} N_{D} f_{E} \\
\frac{C}{w}=L+\Theta N_{D} f_{E} ; \quad \Theta \equiv \frac{1-\beta}{(1-\delta) \beta} .
\end{gathered}
$$

- Dividing the price index of the home country $N_{D} \widetilde{\rho}_{D}^{1-\sigma}+N_{I}^{*} \widetilde{\rho}_{I}^{* 1-\sigma}$ by $\widetilde{\rho}_{I}^{* 1-\sigma} N_{D}$, I obtain

$$
\begin{gathered}
\frac{\widetilde{\rho}_{I}^{* \sigma-1}}{N_{D}}=\underbrace{\left(\frac{\widetilde{\rho}_{D}}{\widetilde{\rho}_{I}^{*}}\right)^{1-\sigma}}_{\left(\frac{\tilde{z}_{I}^{*}}{\tilde{z}_{D}}\right)^{1-\sigma}}+\underbrace{\frac{N_{I}^{*}}{N_{D}}}_{\left(\frac{\tilde{z}_{D} \nabla^{1-\sigma}}{\tilde{z}_{I}^{*} \nabla^{1-\sigma}}\right)^{\frac{1}{1-\sigma}} \frac{N_{D}^{*}}{N_{D}}} \\
\frac{\widetilde{\rho}_{I}^{* \sigma-1}}{N_{D}}=\left[\left(\frac{\widetilde{z}_{I}^{*}}{\widetilde{z}_{D}}\right)^{1-\sigma}+\left(\frac{z_{\min }}{\widetilde{z}_{I}^{*}}\right)^{k} \frac{N_{D}^{*}}{N_{D}}\right] \equiv \Psi_{I} .
\end{gathered}
$$

I can combine the following equations

$$
\left\{\begin{array}{l}
\widetilde{\pi}_{I}=\frac{C^{*}}{\sigma} \widetilde{\rho}_{I}^{1-\sigma}-w^{*} f_{I}^{*} \\
\widetilde{\pi}_{I}=w^{*} f_{I}^{*}(\nabla-1)
\end{array}\right.
$$

to obtain

$$
\frac{C^{*}}{w^{*}}=\nabla f_{I}^{*} \widetilde{\rho}_{I}^{\sigma-1} \sigma
$$

Now, using C.13 and C.15 for the foreign country:

$$
L^{*}=\left[\nabla f_{I}^{*} \Psi_{I}^{*}-\Theta f_{E}^{*}\right] N_{D}^{*}
$$

Since $N_{D}=N_{D}^{*}$ in the steady-state, then $\Psi_{I}^{*} \equiv\left[\left(\frac{\widetilde{z}_{I}}{\widetilde{z}_{D}}\right)^{1-\sigma}+\left(\frac{\widetilde{z}_{D}}{\widetilde{z}_{I}}\right)^{k}\right]$ and $N_{D}^{*}=\frac{\widetilde{\rho}_{I}^{\sigma-1}}{\Psi_{I}^{*}}$ from equation C.15 can define $\widetilde{\rho}_{I}$ as a function of parameters and wages, by substituting (C.15) 
(C.13) and equating it to C.16):

$$
\begin{aligned}
L^{*}+\Theta \underbrace{\frac{\widetilde{\rho}_{I}^{\sigma-1}}{\Psi_{I}^{*}} f_{E}^{*}}_{N_{D}^{*}} & =\nabla f_{I}^{*} \widetilde{\rho}_{I}^{\sigma-1} \sigma \\
L^{*}\left(\nabla f_{I}^{*} \sigma-\Theta \frac{1}{\Psi_{I}^{*}} f_{E}^{*}\right)^{-1} & =\widetilde{\rho}_{I}^{\sigma-1} \\
\frac{1}{L^{*}}\left(\nabla f_{I}^{*} \sigma-\Theta \frac{1}{\Psi_{I}^{*}} f_{E}^{*}\right) & =\widetilde{\rho}_{I}^{1-\sigma} \\
\widetilde{\rho}_{I} & =\left[\frac{1}{L^{*}}\left(\nabla f_{I}^{*} \sigma-\Theta \frac{f_{E}^{*}}{\Psi_{I}^{*}}\right)\right]^{\frac{1}{1-\sigma}} \\
\Psi_{I}^{*} & \equiv\left(\frac{\widetilde{z}_{I}}{\widetilde{z}_{D}}\right)^{1-\sigma}+\left(\frac{\widetilde{z}_{D}}{\widetilde{z}_{I}}\right)^{k} .
\end{aligned}
$$

- Finally, to determine $\widetilde{z}_{I}$, I can substitute equation C.6 to $\widetilde{\pi}_{D}$ as follows

$$
\begin{gathered}
\widetilde{\pi}_{D}=\left(\frac{\widetilde{z}_{I}^{*}}{\widetilde{z}_{D}}\right)^{1-\sigma}(\underbrace{\widetilde{\pi}_{I}^{*}}_{(\nabla-1) w f_{I}}+w f_{I}) \\
\widetilde{\pi}_{D}=\left(\frac{\widetilde{z}_{I}^{*}}{\widetilde{z}_{D}}\right)^{1-\sigma}\left(w f_{I}\right)
\end{gathered}
$$

and then substitute equation C.8. the steady-state ratio $N_{I} / N_{D}=\left(z_{\min } / \widetilde{z}_{I}\right)^{k} \nabla^{\frac{k}{\sigma-1}}$ to C.4, and considering that $\widetilde{z}_{D}=\nabla^{\frac{1}{\sigma-1}} z_{\min }$,

$$
\begin{gathered}
\Xi f_{E} w=\widetilde{\pi}_{D}+\frac{N_{I}}{N_{D}} \widetilde{\pi}_{I} \\
\Xi f_{E} w=\left(\frac{\widetilde{z}_{I}^{*}}{\widetilde{z}_{D}}\right)^{1-\sigma}\left[(\nabla-1) w^{*} f_{I}^{*}+w f_{I}\right]+\left(\frac{\nabla^{\frac{1}{\sigma-1}} z_{\min }}{\widetilde{z}_{I}}\right)^{k}(\nabla-1) w^{*} f_{I}^{*}= \\
\Xi f_{E} w=\left(\frac{\widetilde{z}_{I}}{z_{\min }}\right)^{1-\sigma} \nabla^{2} w^{*} f_{I}^{*}+\left(\frac{z_{\min }}{\widetilde{z}_{I}}\right)^{k} \nabla^{\frac{k}{\sigma-1}}(\nabla-1) w^{*} f_{I}^{*} \\
\Xi \frac{f_{E}}{f_{I}^{*}}=\left(\frac{\widetilde{z}_{I}}{z_{\min }}\right)^{1-\sigma} \nabla^{2}+\left(\frac{z_{\min }}{\widetilde{z}_{I}}\right)^{k} \nabla^{\frac{k}{\sigma-1}}(\nabla-1) \\
\nabla^{2} \widetilde{z}_{I}^{1-\sigma}+\nabla^{\frac{k}{\sigma-1}}(\nabla-1) \widetilde{z}_{I}^{-k}=\Xi \frac{f_{E}}{f_{I}^{*}}
\end{gathered}
$$


which is solved numerically as in Ghironi and Melitz (2005).

Once $\widetilde{z}_{I}$ is determined numerically, all other steady-state variables can be computed in steps similar to Ghironi and Melitz (2005) as follows:

- $\Psi_{I}^{*}$ is derived using using $\widetilde{z}_{I}$ and $\widetilde{z}_{D}$ in C.19 ;

- using $\widetilde{z}_{I}$, equation (C.8) and the labor supply equation, one can derive the equilibrium wage

$$
\begin{aligned}
\widetilde{\rho}_{I}^{\sigma-1} & =L\left(\nabla f_{I}^{*} \sigma-\Theta \frac{f_{E}^{*}}{\Psi_{I}^{*}}\right)^{-1} \\
\left(\frac{w}{\widetilde{z}_{I}} \mu\right)^{\sigma-1} & =w^{\frac{1}{\chi-1}}\left(\nabla f_{I}^{*} \sigma-\Theta \frac{f_{E}^{*}}{\Psi_{I}^{*}}\right)^{-1} \\
w^{1-\sigma}\left(\frac{\mu}{\widetilde{z}_{I}}\right)^{1-\sigma} & =w^{\frac{1}{1-\chi}}\left(\nabla f_{I}^{*} \sigma-\Theta \frac{f_{E}^{*}}{\Psi_{I}^{*}}\right)^{\sigma-1} \\
w^{\frac{(1-\sigma) \chi-\sigma}{1-\chi}} & =\left(\nabla f_{I}^{*} \sigma-\Theta \frac{f_{E}^{*}}{\Psi_{I}^{*}}\right)\left(\frac{\mu}{\widetilde{z}_{I}}\right)^{\sigma-1}
\end{aligned}
$$

and the number of hours worked $L$;

- $N_{D}=\widetilde{\rho}_{I}^{\sigma-1} \Psi_{I}^{-1}$ is computed using using C.15;

- $\widetilde{\rho}_{D}=\frac{\widetilde{z}_{I} w}{\widetilde{z}_{D} w^{*}} \widetilde{\rho}_{I}=\frac{\widetilde{z}_{I}}{\widetilde{z}_{D}^{*}} \widetilde{\rho}_{I}$ using the definition of $\widetilde{\rho}_{D}$ for the average firm with $\widetilde{z}_{D}$ and $\widetilde{\rho}_{I}$ for the average affiliate with $\widetilde{z}_{I}$;

- $C=\left[L+\Theta N_{D} f_{E}\right] w$ using (C.13);

- $N_{E}=\frac{\delta}{1-\delta} N_{D}$ from the law of motion for the total number of firms (C.15);

- $N_{I}=\left(\frac{z_{\min }}{\widetilde{z}_{I}}\right)^{k} \nabla^{\frac{k}{\sigma-1}} N_{D}$ using 23$)$;

- $\tilde{\pi}_{D}=\frac{1}{\sigma} \widetilde{\rho}_{D}^{1-\sigma} C$ using A.6 for the average firm $\widetilde{z}_{D}$

- $\tilde{\pi}_{I}=\frac{1}{\sigma} \widetilde{\rho}_{I}^{1-\sigma} C-w^{*} f_{I}^{*}$ using $\mathrm{A} .12$; 
- $\widetilde{v}=f_{E} w$ from the free entry condition;

- $r=\frac{1}{\beta}-1$ from the steady-state Euler equation for bonds. 